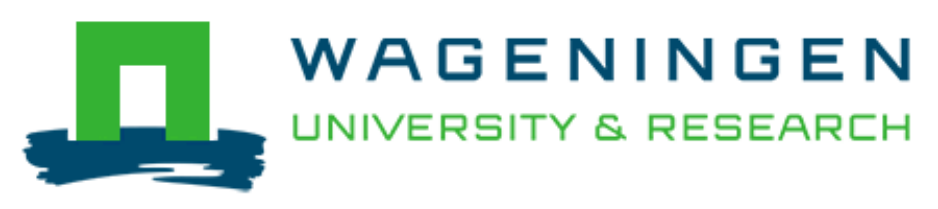

Trends in technology, trade and consumption likely to impact on microbial food safety

Quested, T. E., Cook, P. E., Gorris, L. G. M., \& Cole, M. B.

This is a "Post-Print" accepted manuscript, which has been published in "International Journal of Food Microbiology"

This version is distributed under a non-commercial no derivatives Creative Commons (c) $(\mathcal{\Theta \Theta} \Theta$ (CC-BY-NC-ND) user license, which permits use, distribution, and reproduction in any medium, provided the original work is properly cited and not used for commercial purposes. Further, the restriction applies that if you remix, transform, or build upon the material, you may not distribute the modified material.

Please cite this publication as follows:

Quested, T. E., Cook, P. E., Gorris, L. G. M., \& Cole, M. B. (2010). Trends in technology, trade and consumption likely to impact on microbial food safety. International Journal of Food Microbiology, 139(Suppl. 1), S29-S42.

https://doi.org/10.1016/j.ijfoodmicro.2010.01.043 


\section{Trends in technology, trade and consumption likely to impact on}

\section{2 microbial food safety}

4 T. E. Quested ${ }^{1}$, P. E. Cook ${ }^{1}$, L.G.M. Gorris ${ }^{2, *}$, and M.B. Cole ${ }^{3}$

7 1. Food Standards Agency, 125 Kingsway, London, WC2B 6NH, United Kingdom.

8 2. Unilever, Safety \& Environmental Assurance Centre, Sharnbrook, Colworth Science Park, $9 \quad$ MK44 1LQ, United Kingdom; European Chair in Food Safety Microbiology, Laboratory for 10 Food Microbiology, Wageningen University, Wageningen, The Netherlands.

11 3. National Center for Food Safety and Technology, Summit, Illinois, 6502, U.S.A. (new

12 address since 1-1-2010 to be footnoted: Food Science Australia, North Ryde, Australia)

14 Corresponding author:

15 Leon G.M. Gorris, Unilever, Safety \& Environmental Assurance Centre, Sharnbrook, Colworth

16 Science Park, MK44 1LQ, United Kingdom.

19 Running title:

20 Technology, trade and consumption trends.

22 Keywords:

23 Microbial food safety; Food technology; Globalization 


\section{Abstract}

27 impact on food-borne disease are analysed and the key driving factors identified focusing on the

28 European Union and, to a lesser extent, accounting for the United States and global issues.

29 Understanding of factors is developed using system-based methods and their impact is discussed

30 in relation to current events and predictions of future trends. These factors come from a wide

31 range of spheres relevant to food and include political, economic, social, technological,

32 regulatory and environmental drivers. The degree of certainty in assessing the impact of

33 important driving factors is considered in relation to food-borne disease. The most important

34 factors driving an increase in the burden of food-borne disease in the next few decades were

35 found to be the anticipated doubling of the global demand for food and of the international trade

36 in food next to a significantly increased consumption of certain high-value food commodities

37 such as meat and poultry and fresh produce. A less important factor potentially increasing the

38 food-borne disease burden would be the increased demand for convenience foods. Factors that

39 may contribute to a reduction in the food-borne disease burden were identified as the ability of

40 governments around the world to take effective regulatory measures as well as the development

41 and use of new food safety technologies and detection methods. The most important factor in

42 reducing the burden of food-borne disease was identified as our ability to first detect and

43 investigate a food safety issue and then to develop effective control measures. Given the global

44 scale of impact on food safety that current and potentially future trends have, either by potentially

45 increasing or decreasing the food-borne disease burden, it is concluded that a key role is fulfilled

46 by intergovernmental organisations and by international standard setting bodies in coordinating

47 the establishment and rolling-out of effective measures that, on balance, help ensure long-term

48 consumer protection and fair international trade. 


\section{1. Introduction.}

51 Though there is little quantitative, concrete evidence that the globilization of food production and

52 marketing has an impact on food safety as it is experienced day-by-day by consumers around the

53 globe, it is very likely that globilization of the food supply as well as other global trends put

54 pressure on the burden of food-borne illnesses in many parts of the world. Technological and

55 infra-structural changes in food supply chains and the ever expanding trade worldwide have

56 changed the pace and distances at which an enormous variety of foods are brought to the

57 consumer's home. While consumers benefit by the product variety available to them, the

58 complexity of the global food supply requires more international collaboration and harmonization

59 of management efforts in order for existing and emerging risks to consumers to be dealt with

60 adequately. It is evident that changes in food production, processing, distribution and

61 consumption at a global scale have impacts well beyond the direct health and wellbeing of

62 consumers. They have major economical, social and environmental impacts that need to be

63 considered as part of global management efforts. Likewise, major differences exist in the impact

64 of global or regional changes between developed, emerging and developing economies.

65 This paper has been prepared for the conference "Future Challenges to Food Safety",

66 organised by the Dutch Food and Consumer Products Safety Authority (VWA) and the European

67 Food Safety Authority (EFSA), held in Wolfheze, The Netherlands, from 9 to 12 June 2008. It

68 explores current and potential future trends in the foodborne disease burden around the globe as

69 they relate in particular to technology, consumption and trade of certain foods that are likely to

70 impact on microbial food safety. Developments in food technology and significant changes in

71 consumer demand and food trade around the world over the next decade are discussed. To

72 identify trends and underlying drivers, a system-based approach is taken which analyses how 
73 different drivers currently impact in broad terms on a system of interacting driving factors

74 representing the food system. In so doing, the impact of potential future events on food

75 technology, international trade and consumption is explored. The paper endeavours to present a

76 global perspective on trends influencing the burden of food-borne disease, while taking many

77 examples from the European Union (EU) and its Member States.

\section{Method of Analysis.}

\subsection{Methods for exploring the future.}

The analysis in this paper is underpinned by elements of future studies including horizon

83 scanning and scenario planning methodologies (e.g. Burt and van der Heijden, 2003). The

84 'environment' surrounding the issue of interest, in this case, consumption and trade of food

85 relevant to the disease burden , is understood by identifying factors that affect this issue, and

86 qualitatively assessing the magnitude of interaction between these factors. In so doing, a system

87 composed of these factors is constructed, with the issue of interest at the centre. The behaviour of

88 the system with time can be analysed, thus identifying key factors (drivers) in the operation of the

89 system. This approach helps draw together a wide range of driving factors from many different

90 categories, including social, economic, regulatory, political, technological and environmental

91 drivers (Figure 1).. The inclusion of a broad range of factors put a challenge on the availability of

92 suitable data for the food system build in this study but reduced the number of surprises from

93 parts of the system not normally associated with the issue of interest. Many of the influencing

94 factors are interrelated. For instance, import tariffs may affect availability and price of foods,

95 whereas government campaigns may influence public perception of health benefit. The time-scale

96 of influence varies between factors; some induce gradual change in the system (e.g. demographic 
97 developments), whereas others (e.g. a major outbreak of food-borne disease influencing

98 consumer choice) can impart a specific step change.

99 A key advantage of a system-based approach over, for example, extrapolation of current

100 trends or deterministic modelling, is the handling of uncertainty. Many of the key drivers in the

101 system have large uncertainty associated with them (e.g. oil prices). A system approach allows

102 the impact of the uncertainty stemming from a wide range of factors to be assessed qualitatively,

103 and underpins development of a range of plausible future scenarios, each internally consistent.

104 Furthermore, this approach gives a strong indication of the impact of important drivers, so that,

105 even if their future trajectory cannot be predicted with a large degree of certainty, the driver can

106 be monitored, thus giving forewarning of behaviour in other parts of the system.

2.2. Defining the investigation focus.

The focus of this analysis is the impact of food consumption and trade on the food-borne

110 disease burden. Next to food types, there are elements of the food supply network and consumer

111 behaviour to consider. The latter focus includes trends in foods eaten inside and outside the home,

112 grocery shopping and food-related behaviour (e.g. preparation, storage and consumption

113 patterns).

114 There are a large number of combinations of food-borne disease agents and food vehicles,

115 and this paper focuses on those foods which have been shown to contribute strongly to the burden

116 of food-borne disease, both in number of cases and severity of illness. Studies have been

117 conducted in a number of countries to assess the burden of food-borne disease and, in some cases,

118 to tease out the contribution of particular pathogens, animal sources, food vehicles or

119 pathogen/food combinations (Batz et al., 2005; Hald et al., 2004; Adak et al., 2005; Kemmeren et

120 al., 2006; Evers et al., 2008). 
122 due to, amongst other factors, nature and extent of food contamination, consumer behaviour and

123 consumption patterns. For food-borne disease in England and Wales between 1996 and 2000,

124 Adak et al. (2005) estimated the proportion of cases and deaths relating to food groups using data

125 from the national surveillance database for general outbreaks of infectious intestinal disease.

126 Cases were analysed where a single vehicle of infection was identified by epidemiological or

127 microbiological investigation. These data are reproduced in Table 1. Overall, poultry, red meat

128 such as beef and complex foods (meal dishes consisting of ingredients of various food types in

129 which the precise source of infection was not established) were the two food groups mostly

130 attributed with cases or death. Individual food types which contributed at least $5 \%$ of all cases or

131 at least 5\% of deaths were identified to be chicken, turkey, eggs, beef, mixed / unspecified red

132 meat and milk. Other red meat categories, shellfish, salad vegetables and rice also contributed to

133 a small but significant proportion while dairy products other than milk, cooked vegetables and

134 fruit did not contribute at all. Outbreaks involving fresh produce, whilst not contributing strongly

135 to the burden of food-borne disease in the dataset presented in Table 1, are attracting international

136 concern with respect to food safety (FAO/WHO, 2008) because of the significance of

137 international trade in these commodities. It is important to emphasise that using outbreak data for

138 food attribution may not adequately reflect the vehicles associated with sporadic cases of illness,

139 which form the bulk of the food-borne disease burden, and may also underestimate the

140 contribution of certain pathogens, e.g. Campylobacter or Toxoplasma (Batz et al., 2005;

141 Kemmeren et al., 2006).

142 Relatively high risks for food-borne diseases tend to be associated with those foodstuffs

143 that are least processed, i.e. raw milk, raw or lightly cooked eggs or dishes containing them, raw

144 mince meat (e.g. steak tartare), oysters and to some extent fresh produce. With these foods it is 
145 particularly important to prevent contamination occurring in the first place, as there are limited

146 options for eliminating the hazard(s) through processing or consumer handling.

147 Hughes et al. (2007) used data from food-borne disease outbreaks of infectious intestinal disease

148 in England and Wales (1992-2003) to categorise the food vehicle associated with outbreaks.

149 Common pathogen-food vehicle combinations identified were:

150 - Campylobacter: poultry.

$151 \quad$ - Salmonella: poultry, desserts, red meat, eggs.

$152 \quad-\quad$ Clostridium perfringens: red meat, poultry.

$153 \quad$ - Vero-toxin-producing E.coli O157: Red meat, milk and milk products.

$154 \quad$ - Viruses: fish and shellfish, salad, fruit and vegetables.

155 It should be noted that this study only considered outbreaks of infectious intestinal disease

156 and that the data did not include outbreaks involving Listeria monocytogenes, an important food-

157 borne pathogen in terms of mortality according to the Chief scientist's report (FSA, 2007a). In

158 the few outbreaks in England and Wales, food vehicles for L. monocytogenes have included

159 sandwiches, dairy and meat products (McLauchlin et al., 1991; Gillespie et al., 2006). Elsewhere,

160 the prominent role of this pathogen in foodborne illesses has been well recognised (BIOHAZ,

161 2007; Ontario MoH 2009).

162 Lynch et al. (2006) examined food-borne disease outbreaks in the USA between 1998 and

1632002 and presented data by food vehicle (where known) and pathogen. Whilst some associations

164 are similar to those seen in the outbreak data in England and Wales there were also some

165 differences, such as the relatively high proportion of outbreaks associated with complex foods

166 such as desserts in the UK where it can be difficult to determine the origin of the contamination

167 (Adak et al. 2005). 


\section{3. Results.}

169 The consumption level of a specific food type is influenced by a multitude of factors, reflecting

170 the complex role food plays in our lives. To predict future changes in microbial food safety and

171 the disease burden resulting from possibly changing consumption patterns, understanding the

172 interactions between these influences is important. In Figure 2, the key factors identified on the

173 basis of the qualitative analysis in this work are plotted against their likely effect on the burden of

174 foodborne diseases either positively or negatively and also against the certainty of their impact.

175 The following section explores some of these relationships in more detail for the various

176 categories of drivers.

\subsection{Political Drivers.}

Governments play a critical role in protecting the consumer. However, many countries are poorly equipped to respond to existing and emerging food safety problems. Many lack technical

181 and financial resources, effective institutional frameworks, trained personnel and sufficient

182 information about hazards and risks involved (CSPI, 2005). In many countries political pressures 183 such as civil unrest or particular public health concerns far outweigh concerns about food-borne

184 diseases. Often the desire for a country to grow its economy through food exports is a key driver 185 for investment in food safety infrastructure, though there is a realization that food safety is a 186 prerequisite to support a healthy workforce and developing a successful export business in food.

A governmental agricultural policy can also have a significant impact on consumption

189 Union (EU), it is of interest to ascertain the fraction of foods that are produced within and outside 190 the EU. The country of origin may have implications for microbiological safety. In addition, the 
191 balance of imports and exports for a country characterises how trade and food prices are impacted

192 by world food prices.

193 Considering self-sufficiency of a country or region as the fraction of domestic production

194 divided by domestic use (expressed as a \%), the European Union is self-sufficient in most types

195 of meat (Table 2A), the exceptions being sheep and goat meats (Eurostat, 2008a). Furthermore,

196 EU imports and exports of meats and meat preparations represented only 3\% and 8\%,

197 respectively, of gross apparent human consumption (Eurostat, 2008b). The figures for the total

198 EU mask very different self-sufficiency levels for Member States. In 2004, Denmark and Greece

199 represented the extremes of meat self-sufficiency with the former producing around 3.3 times the

200 amount it consumed and the latter 0.54 (Llorenes Abando and Martinex Palou, 2006). This

201 illustrates the fact that intra-EU trade is more important than extra-EU trade for most Member

202 States.

203

204 3.2. Economic Drivers.

The World Bank estimates that 1.25 billion people live on less than $\$ 1 /$ day with 840

206 million of them suffering under-nutrition or hunger (Thompson, 2007). Some three billion people

207 live on less than \$2/day, which generally buys enough calories to offset hunger. As incomes rise

208 from $\$ 2$ to about $\$ 10$ per day, people eat more meat, dairy products, fruits, vegetables, and edible

209 oils, causing rapid growth in demand for raw agricultural products. Beyond \$10 per day, people

210 buy more processing services: packaging, variety, and luxury forms. Table 3 illustrates the huge

211 potential for poverty reduction in populous key emerging economies and developing countries.

212 The potential market growth for value added products is greatest in countries such as China and

213 India, where there is a huge potential for further population growth as well as poverty reduction.

214 Both population growth and the proportion of presently low-income consumers that are lifted out 
215 of poverty will be important determinants of the future global demand for food. The World Bank

216 estimates that the number of people in developing countries living in households with incomes

217 above \$16,000 per year will rise from 350 million in 2000 to 2.1 billion by 2030. If there is a

$21850 \%$ increase in the world population plus a 50\% increase in broad based economic affluence in

219 low-income countries, then world food demand could double by the year 2050.

220 Food prices are determined, like prices of all products, by supply and demand. However,

221 unlike many other products the demand for food per capita is, to a large degree, invariant of price

222 for high-income countries. As noted by Tansey (2008), the consumption of most goods (e.g. CDs,

223 shoes) can increase manifold without demand being satiated; the same is not true of food.

224 The effect of food price and income level on food demand can be described by price and income

225 elasticities. Price elasticity regarding demand, as opposed to that of supply, for a country is

226 defined by the change in demand due to a change in price. A price elasticity of -1 indicates that

227 an increase in price of, for instance, 1\% leads to a decrease in demand of $1 \%$. A price elasticity of

228 zero indicates that demand is independent of price. Similarly income elasticity is defined by the

229 change in demand due to a change in income level. Notably, price elasticities are descriptive and

230 therefore not necessarily constant over time; they can evolve to reflect perception, price and

231 availability of food.

232 If the amount spent on all food is considered, the price elasticity is relatively small

233 (between -0.4 and 0 in high-income countries) (Regmi et al., 2001). Similarly the income

234 elasticity for total food is small in high-income countries (Schmidhuber, 2003). In contrast,

235 income affects food demand strongly in low-income countries. In China and India, where

236 incomes have been experiencing substantial growth recently, overall food demand has risen

237 sharply, with a large impact on global food demand (OECD/FAO, 2007). 
239 income countries. When analysed at the food-type level, price has a significant effect on the

240 demand. Ordinarily, price elasticities are higher where an available substitute exists and the food

241 in question is perceived as a luxury rather than a staple.

242 Selected price elasticities are shown in Table 2B for large food groups in the United

243 Kingdom (UK; comprising of England, Scotland, Wales and Northern Ireland). In Figure 3, data

244 for Great Britain (GB; comprising of England, Scotland and Wales) show the breakdown for a

245 range of food types. Note that the GB data in Figure 3 are for the mid-income bracket selected as

246 broadly indicative of the population as a whole, whereas the UK data in Table 2B are for all

247 income brackets. As the own-price elasticity values for the large food groups indicate, in general,

248 an increase in price leads to a decrease in demand. Braking food groups down in smaller units,

249 however, does refine the view on this inter-dependency. Figure 3 indicates that bread has a price

250 elasticity close to zero, due to its position as a staple in the diet with few, similarly priced

251 substitutes available. Oils and fats, which hold a similar position in the diet, also have a price

252 elasticity close to zero, whereas butter, which is perceived as a more luxurious product for which

253 substitutes exist, has a price elasticity well below zero.

254 Of central interest to microbial food safety are meat and poultry. These food types have

255 relatively high price and income elasticities and, as such, are likely to see a decrease in demand if

256 food prices were to rise. This effect is likely to be strongest for expensive meats - in Great Britain

257 this position is held by lamb, although this would vary across Europe. Such meats could be

258 substituted by cheaper alternatives - e.g. poultry in Great Britain - and portion sizes may

259 decrease. Such changes could have an impact on the burden of foodborne disease from these

260 sources. 
262 food types important to microbial safety, but what influences price? Figure 4A illustrates the

263 main drivers of the supply price other than demand. Costs that are reflected in the sales price

264 include transportation of goods and waste generated up to the point of sale, marketing and

265 advertising, in addition to production and processing costs. These costs are strongly influenced by

266 the economic environment, with oil and gas prices being key drivers, strongly affecting the cost

267 of, for example, transportation fuel and ammonia-based fertiliser, for which natural gas is a

268 feedstock. Competition for and pressure on land use are other long-term influences that feed into

269 food prices. This is discussed in relation to demographic changes, climate change and biofuel

270 feedstock production.

271 Consumption of major animal derived food groups important to microbial safety is

272 illustrated in Figure 5A for the EU15 (the 15 countries that made up the European Union before

273 the 2004 expansion). The graph shows the change in the gross human apparent consumption per

274 capita, which adds up commercial production, the estimated own account production for self

275 consumption, import and opening stocks and subtracts from this exports, usage input for

276 processed food, feed, non-food usage, wastage and closing stocks. Gross human apparent

277 consumption per capita of fish and seafood in $2001(+8 \%)$ and meat in $2002(+4 \%)$ were higher

278 than in 1995, whereas consumption of milk declined (-6\%) between 1995 and 2002. These data

279 illustrate the fact that, when analysed at this level of food-type and geographical aggregation,

280 consumption levels per capita change relatively slowly. The increased consumption of meat

281 would have been influenced by the reduction in price relative to income; the agricultural output

282 price of meat fell by 19.6\% in real terms across the EU15 countries between 1996 and 2002

283 (Eurostat, 2008 a,b). Unfortunately, no aggregated EU data were available for fresh produce or 
284 eggs, which are food groups that have been more frequently associated with microbiological

285 foodborne illnesses in recent years.

286 A breakdown of the gross human apparent meat consumption per capita by animal is

287 shown in Figure 5B. It reveals that changes in poultry and pork consumption were responsible for

288 the increase observed in meat consumption overall, whereas consumption of sheep and goats, and

289 cattle declined. It is notable that the types of meat for which consumption increased also

290 experienced the most significant prices falls in real terms (see Table 2C for changes between

2911996 and 2002) and this would certainly have been a key factor in the observed shift in

292 consumption patterns.

There have been recent and dramatic increases in agricultural commodity prices. For

294 instance, during 2007 the FAO (Food and Agriculture Organisation of the United Nations) food

295 price index increased by approximately $40 \%$ (FAO, 2008). The increase has been most obvious in

296 dairy products, but is also evident in cereals and oils and fats. Probable drivers for these price

297 changes include increased food demands due to greater population and affluence, high energy

298 prices, competition for land-use from biofuel-feedstock production and poor production

299 conditions in a number of important producer countries, such as droughts in Australia. However,

300 prices of agricultural products are notoriously volatile, with sharp but brief peaks and persistent

301 slumps. Since peaking mid 2008, agricultural commodity prices have fallen sharply, whilst food

302 prices have declined but not as much (FAO, 2009; OECD/FAO, 2009).

303 In cases where food prices are higher due to increased demand, the difference between

304 costs and commodity prices should increase and some of this difference could boost farmers'

305 income. In contrast, where food prices are higher due to increased production costs, this could put

306 downward pressure on farmers' income. The former case would represent an opportunity for 

agricultural investment, and indeed, investment could be encouraged in areas beneficial to

308 microbial food safety.

The growing global trade in food means that food supply structures are complex and ever-

310 evolving: rather than the traditional view of a linear supply chain, these structures now resemble a

311 network akin to the Internet. Food components entering the supply network can be distributed and

312 used in a wide range of products, which can make traceability in the case of a contamination

313 incident a major issue, e.g. the occurrence of the illegal food colour Sudan I in a wide range of

314 foods (Sudan I Review Panel, 2007).

315 The food supply network has seen numerous changes that enable the food supply network

316 to benefit from economies of scale, with consolidation of, for example, suppliers of agricultural

317 inputs (Tansey, 2008) and retailers (UK Prime Minister’s Strategy Unit, 2008). Moreover, there

318 has been greater co-ordination between companies, both those interfacing vertically in the supply

319 network, and, in the agricultural input sector, horizontally via alliances between companies in

320 similar fields (Tansey, 2008). Structural changes within this supply network have been occurring

321 and this is likely to continue. If these changes and their implications for microbial food safety are

322 not fully considered and managed, there is the potential for a significant impact on public health.

323 Worldwide there are already examples of outbreaks of huge magnitude. In 1988, a Hepatitis A

324 epidemic in China associated with the consumption of clams affected 292,000 people, killing nine

325 of them (Rocourt et al., 2003). In a 1996 Japanese outbreak, at least 9,578 individuals (mainly

326 schoolchildren) suffered from severe E. coli O157:H7 infections linked to white radish sprouts

327 (Mead et al., 1999). In 2000, an outbreak from milk in Japan resulted in almost 6,000 illnesses;

328 the contamination point was a production line valve that became contaminated (Adak et al., 329 2002). 
331 require the use of new risk management tools that allow the management of risk at appropriate

332 points in the food chain.

\subsection{Social Drivers.}

Price is not the only factor determining food consumption patterns, with choices also and the USA (Datamonitor, 2006). These drivers are illustrated in Figure 4B, alongside other concerns regarding sustainable living and animal welfare (e.g. intensive production, organic, fair

341 trade and carbon footprint). Changes in the public's perception to food quality are complex and difficult to predict. Furthermore, the difference in perception between countries is marked.

343 Alongside gradual shifts in perception, punctuated change occurs as. illustrated by the sharp

344 reduction in egg consumption in the United Kingdom in 1988, after a significant change in the

345 perceived risk from Salmonella Enteritidis.

347 instance, the United Kingdom public named the following organisations when asked who

348 provided their information on food safety and food scares: Government Departments,

349 supermarkets, local councils, food manufacturers, consumer groups and the media (FSA, 2007b).

350 Where accurate and balanced information on food safety is available to the public, there is the

351 possibility for self-control in the system relating to consumption of foods associated with a risk.

352 For instance, to an extent, the public seek to minimise their exposure to food-based risk and 353 access to information can aid this minimisation. An example of this is the reduction in foodborne 
354 disease in Los Angeles after the hygiene ratings of restaurants were displayed at the entrances of

355 premises (Zhe Jin \& Leslie, 2003). In this case, enforcement activities on accessibility of

356 information impacted on consumption behaviour and the foodborne disease burden.

357 Convenience is currently a key factor in determining food choices. This trend is due in

358 part to increased time pressure on people’s lives, which has manifested itself in a reduction in

359 food preparation time (Cheung et al., 2007). Other related trends include the increase in

360 supermarkets' share of the grocery market and consumption of foods requiring less preparation

361 time, e.g. ready meals (UK Prime Minister’s Strategy Unit, 2008). This increase in supermarkets’

362 share of the grocery market has not been confined to large stores. The creation in recent years of

363 smaller high-street supermarket outlets with extended opening hours reflects the trend in Europe

364 and the US of fewer large shopping trips, in favour of more 'immediate' grocery shopping

365 (Datamonitor, 2008). Interestingly, the increase in the number of products available has reached

366 the point where consumers would prefer less choice. This became evident in a recent consumer

367 survey in Europe and the USA, where it was found that more consumers agreed than disagreed

368 with the statement the there is now too much choice when making most purchase decisions

369 (Datamonitor, 2008).

370

Taking the UK as an example, consumers spend a greater proportion of their food budget

371 eating out than they have done in the past, although in the last 5 years, this trend has levelled out.

372 This reflects the increase in disposable income available relative to food prices (UK Prime

373 Minister’s Strategy Unit, 2008). Although convenience is a strong driver, other preferences

374 relating to consumer behaviour are exerting themselves, such as an increasing desire for home-

375 cooking, and an associated aspiration to increase fresh ingredient usage (Datamonitor, 2006). It is

376 noted, however, that these desires are not often realised due to time pressures. This has led to the

377 recent development of products that facilitate 'meal assembly', i.e. the use of semi-prepared 
378 ingredients to create a meal. The use of meat products, including marinated and semi-cooked

379 variants, has the potential to impact on foodborne disease if information on preparation, cooking

380 and storage is not clearly conveyed to or followed by the consumer.

381 The trend in convenience has seen an increase in the ready meals market, which is still 382 growing fast in established markets such as in Spain, Italy and other southern European countries.

383 The largest and most developed market in ready meals is in the US where, overall, it is growing

384 more slowly. However, an exception is the market for chilled ready meals. This is the fastest

385 growing sector of the ready meals industry and is expected to grow at CAGR (compound annual

386 growth rate) of 3.8\% between 2004 and 2009 to reach US\$9.0 billion (Eastwood, 2006). These

387 trends in convenience foods can lead to the emergence of new microbial hazards. An example of

388 this was the development of the chill supply chain in the UK throughout the 1970s and 1980s.

389 This manufacturing and supply chain provided favourable conditions for the contamination and

390 growth of L. monocytogenes in ready to eat foodstuffs. Although several other foodborne

391 pathogens (e.g. Yersinia enterocolitica, psychrotrophic Bacillus cereus and non-proteolytic

392 Clostridium botulinum) may be able to grow at refrigeration temperatures, the significance of $L$.

393 monocytogenes as a foodborne pathogen in the UK was not fully recognised until there was a

394 rapid increase in human cases of listeriosis in the late 1980s. Contamination of pate with $L$.

395 monocytogenes has been suggested as a likely contributory cause of this increase since the 396 subsequent decline in cases has been attributed to the issuing of government warnings on pate

397 consumption to vulnerable groups and the withdrawal of the likely contamination source

398 (McLauchlin et al., 1991). Testing of the chill supply-chain infrastructure and retail foods at the 399 time revealed widespread contamination with L. monocytogenes, and this precipitated an 400 extensive cleaning operation to address the problem (Malcolm Kane, personal communication). 401 The above illustrates the need for understanding and communication throughout the industry of 
402 the implications for food safety of structural changes in supply-chain infrastructure or the

403 introduction of novel food concepts. An example of the latter may be the so called 'Not-Ready-

404 To-Eat' (Not-RTE) foods. Not-RTE foods in the US are considered 'raw' for the purposes of

405 current regulatory focus regarding sanitary conditions and presence of pathogens, whereas

406 Ready-To-Eat (RTE) products are identified as safe to consume without further lethality

407 treatment. Heating of RTE products may be applied for palatability purposes but is not required

408 to ensure product safety. The growing market for Not-RTE, providing particular convenience to

409 consumers, has lead to food safety concerns since a number of outbreaks have occurred recently

410 with Not-RTE products in the US. Mostly, these were due to the consumer not properly reheating

411 or cooking products that require thorough cooking to ensure product safety. Frequently the

412 products involved appear like they may be already cooked, for example pre-breaded raw poultry

413 products, and often microwave re-heating is also an important factor (FSIS, 2006).

414 Other recent trends in consumer patterns include the rise of so-called ethical foods,

415 including elements of organic production, fair trade, assurance of farming standards and animal

416 welfare. Associated with these trends is a growing emphasis on local produce. The degree of

417 uptake varies strongly between countries and in part is due to availability of products, and

418 willingness to pay a premium for these goods, which in turn depends on perceived benefits and

419 relative income levels.

420 Public bodies in many countries are actively engaged in promotion of a balanced,

421 nutritious diet. The funding for these activities may grow in light of the obesity problem many

422 countries are experiencing and the associated increase in healthcare costs. Such a trend has the

423 ability to influence food choices relevant to microbial food safety. If protein sources high in

424 saturated fats are discouraged in favour of alternatives, red meat consumption could decline in

425 favour of poultry, fish and vegetarian options. Specific nutrition-related activities could also 
426 affect microbiological safety in particular ways, e.g. reducing salt levels in processed foods could

427 shorten the shelf-life of certain products unless such foods are reformulated to ensure there are

428 adequate preservation hurdles to prevent or minimise growth of microorganisms of concern.

$429 \quad$ Fresh produce consumption could also be encouraged as an alternative to processed foods.

430 In the UK, the awareness of eating a minimum number of fruit and vegetable portions a day rose

431 from 43\% in 2000 to 71\% in 2006 (FSA, 2007b), which has been accompanied by a 9\% increase

432 in the weight of fruit and vegetable purchases (excluding potatoes) between 2001/2 and 2005/6

433 (Expenditure and Food Survey, 2008). Although fresh fruit and vegetable are important to the

434 health and well being of the consumer from a nutritional standpoint, in the last few years the 435 number of reported outbreaks of food-borne disease associated with fresh produce has increased

436 considerably (FAO/WHO, 2008). Outbreak attribution data in the US (CSPI, 2006) suggests that

437 fresh produce is the leading cause of food borne disease in terms of number of case in the US,

438 with salads accounting for about a quarter of this burden. From a global perspective, leafy green

439 vegetables also currently represent the greatest concern in terms of microbiological hazards

440 associated with fresh produce. Leafy greens are grown and exported in large volume, have been

441 associated with multiple outbreaks with high numbers of illnesses in at least three regions of the

442 world, and are grown and processed in diverse and complex ways, ranging from in-field packing

443 to processed bagged product (FAO/WHO, 2008). With the possible exception of irradiation in the

444 USA, there is currently no single, fully effective and validated kill step in the production of leafy

445 greens. Though not fully effective, washing and chlorination are often used for leafy greens and

446 can contribute to an ultimately validated kill step. Notably, for leafy greens, food safety often

447 relies on prevention of contamination during growing and harvesting, which can be a relatively

448 weak form of hazard control, especially in a raw agricultural setting, when used without

449 additional control measures. 
451 preferences. The nature of this role will be determined by how food brands and retailers wish to

452 be portrayed - e.g. as having the public’s health as their concern - and how advertising regulation

453 and implementation develops with time. The increasing number of communication technologies

454 available is likely to alter the methods used to influence consumer choice.

455 A large proportion of food choices can be described as 'inherited', whereby people

456 purchase products and food types that they have historically bought. This practice may be

457 strengthened in the future with the increase in on-line shopping, whereby the customer has the

458 option to build up their current purchase using a previous shopping basket as the starting point.

459 Other shifts in food preferences that are more minor on a global scale or that are more

460 specific to a country or a region are highly difficult to predict and are influenced by a wider range

461 of factors than discussed in this paper. For this reason, this is an area of consumer behaviour

462 where monitoring trends is likely to be more effective than prediction.

463 Global food demand is closely linked to global population, which is predicted to rise from

$464 \quad 6.6$ thousand million people in 2008 to between 7.4 and 7.8 thousand million in 2020 (United

465 Nations World Populations Prospects, 2006). Thus, the world food demand is likely to grow

466 substantially over this period, not only from this rise in population, but also from an increasing

467 urban and affluent population in countries with emerging economies, as detailed by Schmidhuber

468 (2003) and typified by China and India in recent years. These trends will continue to exert an

469 upward pressure on food prices and could reduce the global availability of certain foods.

470 In contrast to the world population, Europe's population is predicted to be relatively

471 stable, reducing from 730 million in 2008 to 720 million in 2020 (reference as in previous

472 paragraph). Given that the EU is self-sufficient in many food types that may impact on foodborne

473 disease (e.g. Table 2A), this creates a degree of security of food availability in the future and a 
474 moderating influence on food prices in Europe relative to global prices. As noted by the UK

475 Prime Minister's Strategy Unit (2008), it is the food-importing developing countries that are

476 likely to face the biggest challenges as a result of increasing world food prices.

Although the population of Europe is set to remain relatively constant, the age structure is estimated to alter significantly, for example, predictions show that in 2020, 30\% of Germany’s

479 population will be 60 years old or above, compared with $25 \%$ in 2005 and 37\% by 2050 (United

480 Nations World Populations Prospects, 2006). The susceptibility to and severity of many

481 foodborne diseases increases with age: e.g. the increase in listeriosis cases noted in several EU

482 countries in recent years has been seen mostly in the elderly population (Denny and McLauchlin, 483 2008; Goulet et al., 2008), and the proportion of Campylobacter cases requiring hospitalisation

484 has increased markedly in the patients over 75 years old (Gillespie et al., 2005). The reasons for 485 the increased severity and susceptibility are not fully understood but are likely to include a 486 lowered efficiency of the immune system and oxidative damage leading to ageing and increased 487 vulnerability to diseases related to the occurrence of cellular damage for instance due to the 488 action of reactive oxygen species. In addition, other physical and mental deterioration, food 489 choices and behaviours may play a role. Although physical deterioration is not solely determined 490 by age, it is likely that the increase in the population of older people will put upwards pressure on 491 the foodborne disease burden. It should also be noted that the food choices of tomorrow's older 492 people will not necessarily be the same as today's older generation. Migration into and away from Europe will continue to be affected by EU expansion, 494 relative income, perceived quality of life, immigration rules and the extent of conflict zones 495 around the world. The future trajectory of these drivers is hard to predict, but they are likely to 496 influence the food preferences within Europe. If immigration causes a major shift in food 
497 consumption and preparation techniques, it is possible for this to alter the burden of foodborne

498 disease.

499

500 3.4. Technological Drivers.

$501 \quad$ For many decades, the food sector investment level has been relatively low as compared

502 to that in the industrial sectors. In recent years, return on investment of broad benefits derived

503 from agricultural research has provided tangible measurement of the substantial value of research

504 and development (R\&D) in agriculture (Onwulata et al., 2008). Despite this, a decade or so of

505 focus on consolidation and efficiency has left investments in R\&D in the food industry extremely

506 low compared to other industry sectors. For example, investment in R\&D as a percentage of

507 value of production in the food sector for Europe was $0.32 \%$ in 2003 and for the United States

508 was $0.39 \%$ in 2002, compared to the chemical, rubber, plastics and fuel products in OECD

509 countries of $2.72 \%$ in 2001 . The lack of investment in innovation has also seen the food industry

510 become one of the least profitable industry sectors. Clearly, an increase in investment will be

511 needed if the food industry is to overcome many challenges of globalization and realize the

512 growth opportunities of meeting important consumer drivers such as health, convenience,

513 pleasure and environmental awareness. Indeed, new product development was selected as the

514 most important investment area for building competitive advantage by a global panel of food and

515 drink executives surveyed by Business Insights in December 2006 (Meziane, 2007). Recent

516 advances in food science and technology, such as novel preservation technologies, offer exciting

517 new possibilities for innovation to meet the above mentioned consumer drivers. Despite the

518 opportunities, care should be taken not to introduce new food safety hazards through deploying

519 new technologies. For example, most novel preservation technologies such as non-thermal

520 treatments cannot currently be relied upon to inactivate bacterial spores which means that they 
521 must be combined with an additional preservation hurdle such as refrigeration or acid formulation

522 to prevent spore outgrowth (Food Safety Magazine Panel, 2007).

523 In the last few years there has been growing research and commercial interest especially

524 in Europe and the United State in a number of specific non-thermal or cold pasteurization

525 techniques. Interest in, for instance, high pressure processing (HPP), UV treatment, pulsed

526 electric field treatments and ionizing irradiation has been fuelled by a continuing consumer desire

527 for foods that appear fresh, but are also convenient and safe. A decontamination step that does not

528 significantly alter the organoleptic or nutritional qualities of the food would have obvious

529 advantages. Cold pasteurization technologies offer the promise of foods that have a freshness of

530 flavour, colour, texture and nutritional value closer to non-heated products while, at the same

531 time, exhibiting enhanced microbiological safety.

532 Of the preservation technologies that are novel in terms of practical application, HPP has

533 probably advanced further than any of the other alternative physical food processing

534 technologies. One of the major processing advantages is that pressure is transmitted uniformly

535 and instantaneously throughout the food product, therefore there is no gradient of effectiveness

536 from outside to inside as there is with thermal processing. Due largely to the advancement of the

537 engineering of the equipment, HPP has become an economically viable process in the last decade

538 or so. Today, high pressure ‘pasteurization' has become a commercial reality with over 120

539 commercial operations worldwide. Several fruit- and vegetable-based refrigerated food products

540 are currently on the international market, including a range of juices and fruit smoothies, jams,

541 apple sauce-fruit blends, guacamole and other avocado products, tomato-based salsas and fajita

542 meal kits containing acidified sliced capsicum and onions and heat and serve beef or chicken

543 slices (acidified and precooked). Additionally, ready-to-eat meat products and seafood, including

544 oysters, are on the market in the U.S. and Europe (Smelt, 1998; Stewart and Cole 2001). The use 
545 of HPP for the pasteurization of sliced meats is an excellent example of how the technology can

546 be used to both enhance food safety and meet consumer trends. The technology provides a robust

547 in pack pasteurization with respect to $L$. moncytogenes with relatively little impact on product

548 quality. It also allows manufacturers to eliminate preservatives from the formula and to be able to

549 make an 'all natural' claim in the US. Another potential for the technology is in the inactivation

550 of foodborne viruses in shellfish (Grove et al., 2006). HPP uses pressures of approximately 300 to

$551700 \mathrm{MPa}$ for a few seconds or minutes to destroy vegetative microorganisms, and can be thought

552 of as a "cold pasteurization" process. Typically, 10 min exposure to HPP in the range of 250-300

553 MPa or 30-60 sec exposure to HHP in the range of 545-600 MPa exerts a pasteurization effect

554 (Hoover, 1997). Notably, microorganisms are quite variable with regard to their sensitivity to

555 HPP. Results of experiments conducted by Shigehisa et al. (1991) suggest that the order of

556 sensitivity to HPP is Gram-negative bacteria > yeasts > Gram-positive bacteria > bacterial spores.

557 Bacterial spores are actually highly resistant to HPP, even to pressures of up to $1000 \mathrm{MPa}$

558 (Timson and Short 1965; Sale et al., 1970; Cheftel, 1992), and hence a combined treatment of

559 parameters such as pressure, mild heat and low $\mathrm{pH}$ is typically required for inactivation and

560 control of outgrowth.

561 Ultraviolet (UV) treatment is another non-thermal technology that holds considerable

562 promise in food processing as an alternative to traditional thermal processing. Its applications

563 include pasteurization of juices, post lethality treatment for meats, treatment of food contact

564 surfaces and extending the shelf-life of fresh produce. This technology is a particularly attractive

565 cold pasteurisation option for certain high throughput liquids such as beverages. Studies such as

566 that of Koutchma et al. (2006) have allowed the technology to be validated as an alternative to

567 heat pasteurisation for juices requiring a 5 log kill of Salmonella spp. in the USA. 
A technology showing promise for food quality but one that is yet to be commercialised is

569 Pulsed Electric Field (PEF) treatment. PEF technology utilizes high strength electric fields,

570 typically up to $50 \mathrm{kVolts} / \mathrm{cm}$, in extremely short time pulses ranging from a few microseconds to

571 milliseconds. Other parameters of PEF processing include the number of pulses given, typically

572 less than 100, as well as the pulse shape, including exponential decay, square, wave or oscillatory

573 pulses. The pulses may also be monopolar or bipolar. With PEF processing, food is treated for a

574 short period of time and the energy lost due to heating of food is minimal, therefore the efficiency

575 of the process is high (Qin et al., 1996).

576 Perhaps one of the oldest and most studied non-thermal technology is food irradiation,

577 which is approved as a food processing method in 43 countries including the U.S., the UK,

578 Belgium, France and the Netherlands. There is an extensive amount of information available in

579 the literature about food irradiation, including reviews by Radomyski et al. (1994), Monk et al.

580 (1995), Farkas (1998) and Barbosa-Canovas et al. (1998). There are currently two main methods

581 of producing the ionizing radiation sources for food applications: gamma radiation and electron

582 beam radiation. Gamma radiation is the traditional radiation method and the radioisotope used in

583 most commercial facilities is cobalt 60 . The mechanisms for microbial inactivation by irradiation

584 are well known. Irradiation irreversibly damages microbial DNA leading to the inability of the

585 organism to reproduce. There are over 45 years of extensive studies documented in the scientific

586 and technical literature detailing chemical and microbial effects of irradiation of food and

587 reporting decimal reduction times ( $\mathrm{D}_{10}$-values) for most foodborne pathogens and many food

588 spoilage organisms. A data analysis of $\mathrm{D}_{10}$-values achieved with irradiation for bacteria and

589 spores has been undertaken and provides approximate estimates of this parameter that can be

590 useful in designing and evaluating irradiation processes under various conditions (van Gerwen et

591 al., 1999). The World Health Organisation has approved irradiation dosages for foods of up to 10 
592 kilograys (kGy) as “unconditionally safe for human consumption”. Despite this, the key

593 impediment for the commercialization of food irradiation is consumer acceptance. Technically,

594 food irradiation provides a highly effective mitigation measure for foodborne microorganisms

595 and its commercialization would be expected to have a profound effect on the incidence of

596 foodborne diseases globally. However, the consumer attitude to food irradiation is a complex

597 issue in which acceptance of the technology may ultimately be weighed against the risks of

598 illnesses due to foods. For example, acceptance of irradiated foods increased significantly when

599 the consumer was provided with information on the advantages of the technology in terms of

600 enhanced product safety and wholesomeness of the product (Bruhn, 1998). At the moment still, it

601 is very difficult to predict whether consumer acceptance would ever allow its commercial use in

602 mainstream food industry.

603 Innovations in our ability to assess and quantify harmfull micro-organisms underly a quite

604 different area of technological drivers. The attribution of an adverse public health effect such as

605 illness to a particular pathogen requires detection of the particular pathogen, which might be at

606 the health care provider or local health department level. Investigation usually includes case

607 definition, symptoms and severity of the disease and an investigation of how illness occurs along

608 with sources of exposure. Surveillance helps to understand the trends in incidence of the disease

609 and role of specific foods. Surveillance is also important in the consideration of potential control

610 strategies by identifying which steps in the food chain could offer the most effective control

611 measures (Tompkin, 2007). Surveillance is crucial to monitor the impact of any resulting control

612 measures or public health policy (ICMSF, 2006). Advances in subtyping technologies (e.g.,

613 PFGE) and information technologies permit human and food isolates to be accurately matched,

614 resulting in the identification of foodborne outbreaks that until recently would have gone

615 undetected. In particular, the fields of 'omics' data generation, bioinformatics driven data analysis 
616 and systems biology offer great opportunities for specific data generation to better understand the

617 resilience of microbial pathogens in foods and assess preservation targets. In combination with

618 new developments of detection systems for food-borne pathogens as well as the development of

619 new predictive models these fields hold the promise for significantly furthering our understanding

620 of the biological systems at hand both at the level of the microorganism but likely also at the level

621 of the host as discussed elsewhere (Havelaar et al, accepted; Brul et al., 2006, 2008).

622 Although not a processing technology, developments in the science of food safety

623 management and risk management for the purposes of this paper could also be considered a

624 technology capable of having a profound impact on our ability to reduce the burden of foodborne

625 diseases (ICMSF, 2002; Gorris et al., 2007). Control measures for particular microbial hazards

626 are developed based on an understanding of both the food vehicle as well as the parts of the food

627 chain that would be most effective in applying the control measures to. For instance, in the case

628 of L. monocytogenes contamination of RTE meat products in the US (Tompkin, 2007) control

629 measures for L. monocytogenes included: preventing recontamination after the kill step by

630 detecting and eliminating environmental harborage sites, improving equipment design to facilitate

631 cleaning, the addition of inhibitors to products (e.g., lactate, diacetate) and pasteurizing packaged

632 product (i.e. steam, hot water, ultra high pressure). Alternative control measures available for

633 fruit juices achieving the 5 log kill of Salmonella and other enteric pathogens required in the US

634 may well have contributed to a significant reduction of fruit juice associated outbreaks since the

635 requirement was introduced in 2002 (Scott and Huffman, 2007, Vojdani et al., 2008).

636 Increasingly, the development of control measures is based on public health risk and is outcome

637 based, which leaves flexibility on how different operations chooses to apply the required degree

638 of control (ICMSF, 2002). In addition, the complexity of today's food safety issues frequently 
639 means that the problem cannot be solved with one single control measure but instead requires a

640 combination of measures to effectively reduce risk.

641

642 3.5. Regulatory and Trade Drivers

643 An increase in the number of incidents related to food safety in recent years has led to

644 nothing less than a paradigm shift in the way that food safety is managed. Regulatory efforts

645 internationally have been focused on the use of risk assessment tools to drive food safety policy

646 and standards away from prescriptive to outcome based control measures. The safety of foods in

647 international trade is a matter often discussed by the World Trade Organisation (WTO, 1994)

648 which recognizes that governments have the right to reject imported foods when the health of the

649 population is endangered. The criteria used to determine whether a food can be considered safe

650 should be clearly conveyed to the exporting country and should be scientifically justifiable. In

651 order to achieve this, the term 'appropriate level of protection' has been used, which is defined as

652 "the level of protection deemed appropriate by the member country establishing a sanitary or

653 phytosanitary measure to protect human, animal or plant life or health within its territory”.

654 Traditionally, and specifically for contaminants and toxins deemed unavoidable in foods, this has

655 been defined in terms of having a chemical or microbial risk "as low as reasonably achievable"

656 (ALARA). This definition has caused great difficulties for a number of reasons. Although trade is

657 becoming increasingly global, the technological capabilities of different countries, and even

658 different companies within the same country, remain very different. Also, the idea of what is

659 considered "reasonable" differs from country to country and a society’s sense of acceptable risk

660 is in part culturally defined.

661 Developments in the areas of predictive modelling and risk assessment now offer the

662 potential to link characteristics of the food chain and the microbial hazards to the exposure and 
663 further to the likely number of cases of illness in the population and are driving new risk

664 management approaches based on concepts such as of Food Safety Objectives and Performance

665 Objectives (CAC, 2007). The approach enables the food industry to meet a specific objective

666 through the application of the principles of Good Hygienic Practice (GHP) and Hazard Analysis

667 Critical Control Point (HACCP), which are established on the basis of performance criteria,

668 process- and/or product-criteria and other control measures that are appropriate for the particular

669 food, the food operation and the food-supply chain involved. It provides a scientific basis that

670 allows industry to select and implement control measures specific to its operations. This approach

671 should also enable regulators to, where necessary, better select "safe harbour” control measures

672 for industry that are based on process-based (prescriptive) standards and are assumed to satisfy

673 performance-based (outcome) standards.

674 The new risk management approaches that are outcome based offer flexibility of

675 operation, which can be very important when considering the most effective control measures in a

676 particular region or operation. However, perhaps the most critical aspect of these new

677 developments in terms of the global foodborne disease burden is whether such new approaches

678 allow for food safety control measures and regulations to be developed and implemented more

679 rapidly, for instance by the development of novel analytical tools for rapid near real-time

680 detection.. Many of the food safety issues that societies face today are more complex in nature,

681 frequently requiring through-chain approaches and relying on more than one control measure to

682 effectively manage risk. It is envisaged by regulators around the world that the new risk

683 management guidelines will offer a framework that will facilitate communication between

684 stakeholders on the most effective food safety management options thereby speeding the

685 development of effective risk management. A good example of a recent CODEX code that

686 benefited from these developments is the Code of Hygienic Practice for Powdered Formulae for 
687 Infants and Young Children (CAC, 2008). This code addresses the emerging public health threat

688 of Cronobacter spp. (previously referred to as Enterobacter sakazakii), which was brought to the

689 attention of Codex Alimentarius in 2002/2003 who then asked FAO and WHO (World Health

690 Organisation) to convene an expert consultation on the topic in February 2004 (FAO/WHO,

691 2004). The consultation used risk management principles to look at a range of control strategies

692 during both manufacture and subsequent use of powdered infant formulae that could be

693 implemented to reduce risk. Importantly, the approach facilitated the formulation of urgent advice

694 to different stakeholders, including caregivers of infants, consumers and industry and ultimately

695 led to a timely update of the code in 2008 (CAC, 2008).

696 Alongside the proportion of different food types being consumed, the origin and

697 production method are also important to microbial safety. Where food comes from is determined

698 by another set of inter-connected factors which include development of trade links, levels of

699 import tariffs, geographic proximity of exporter and importer countries, transport costs, exchange

700 rates, and relative costs for production, manufacturing and storage costs. Trade links, which are

701 closely connected to import tariff levels, develop over a relatively long time-scale. In contrast,

702 exchange rates can fluctuate on a much shorter time scale (hours or days), influencing choice of

703 supplier, although variability is reduced by the practice of agreeing fixed exchange rates for the

704 duration of contracts. The importance of geographical proximity is determined by the type of

705 food (e.g. stability, durability), transportation and storage costs, and social acceptability of

706 transportation over longer distanced versus local production. Recent negotiations relating to

707 global trade are, in general, reducing the level of import tariffs and liberalising global trade. One

708 example is development of the Economic Partnership Agreements between the EU and members

709 of the Africa, Caribbean and Pacific group. These would allow specified countries quota-free and

710 duty-free access to the EU markets. Although this has the potential to radically increase the 
711 amount of food imported into the EU, in practice it is likely that change will be gradual as many

712 of the relevant exporter countries do not have the capacity to fill their current quotas (Stevens et

713 al., 2008). Furthermore, imports in food types important from the perspective of microbial safety

714 (i.e. foods of animal origin) are relatively small compared with apparent consumption in the EU

715 whereas the trade in fresh produce in the region is significant.

716 Although most food groups that impact on microbial safety are likely to see only a gradual

717 shift in supplier countries, foodborne disease may still be substantially affected. Microbial

718 contamination incidents and outbreaks relating to food can be caused by a small proportion of

719 food consumed, and thus foodborne disease patterns can be affected disproportionately to the

720 change in trade. Therefore identifying problems with particular food groups associated with

721 potential supplier nations is important in identifying future risks.

722 Another driver that could lead to further food imports into the EU is reform of the

723 Common Agricultural Policy (CAP). Recent changes have seen subsidy decoupled from

724 production, with the resulting reduction in food stocks held. Further reform of the CAP is in the

725 pipeline, and, although the outcome is uncertain, there is the potential of further reduction in CAP

726 subsidy levels, which could put financial pressure on EU producers.

\subsection{Environmental Drivers.}

The predicted doubling in the global demand for food by 2050 will increase the need to

730 use more land for agriculture. Of all the potentially arable land, currently only around $12 \%$ is not

731 forested or subject to erosion or desertification. One way to meet the future demand for food

732 would be double the area of farm production, but this would have catastrophic effects on the

733 environment through destruction of forests and loss of wildlife habitat, biodiversity and carbon

734 sequestration capacity. Options such as making non-arable land arable or rework eroded land to 
735 arable may not be readily feasible.The only environmentally sustainable alternative is therefore to

736 double productivity on the fertile, non-erodible soils already in crop production. The same forces

737 will also see the demand for products from forests increase and at the same time biofuels

738 production is claiming more and more land (Global Environment Facility, 2002).

739 Importantly, producing food is extremely costly in terms of water use. As examples, the

740 following water demands have been estimated (Ron Sandland, CSIRO, Personal Communication)

741 for the production of one slice of white bread, $28 \mathrm{~L}$; one bottle of wine, $360 \mathrm{~L}$; one potato, $500 \mathrm{~L}$,

742 one 225 g steak, 4660 L. Overall, farmers use an estimated $70 \%$ of the fresh water used in the

743 world. In order to meet the future demands for food the world's farmers will need to more than

744 double production using less water than today. This will inevitably put more pressure on the use

745 of re-claimed water, which will have an impact on food safety.

746 The world's arable land and fresh water are not distributed around the world in the same

747 proportions, as is population. With predicted population growth, urbanization and broad-based

748 economic development the food consumption of many less developed countries will outstrip their

749 production capacity and it is likely that they will become larger net importers.

$750 \quad$ Meteorological effects that could impact on food production include increased air

751 temperatures, and a shift in rainfall patterns including a general increase in extreme weather

752 events, e.g. storms causing crop damage and flooding. Furthermore, drought-prone areas are

753 likely to increase in extent, leading to loss of fertile land, southern Europe being one such

754 example. In contrast, increased water availability and temperature in high-latitude areas could

755 lead to no loss of, or even an increase in, cereal production. However, some of these benefits

756 could be offset by crop damage from waterlogged soil and storms, pests and diseases. The impact

757 on primary production will depend on the how adaptations to the new environment in agriculture 
758 are managed. Aside from agriculture, increased sea temperatures are likely to put further strain on

759 aquaculture (International Panel on Climate Change, 2007).

$760 \quad$ Alongside these direct effects, significant indirect effects in response to climate changes

761 could also occur. For example, the development of taxation and trading schemes related to the

762 release of greenhouse gases have the potential to transform not only agricultural practices, but

763 also have a huge impact on consumption of key food groups. Currently the different stages of

764 food production, manufacturing and delivery experience different levels of emission levies - for

765 example, in the UK methane emissions direct from cattle or nitrous oxide releases from fertiliser

766 use are not subject to a levy, in contrast to fuel used by tractors to work the land. If the full

767 economic cost to society from all parts of the production and delivery chain were included in

768 such levies, the price of certain meats would rise relative to many other foods, thus substantially

769 reducing their consumption, with a potential reduction of the impact on foodborne disease.

770 Whether such changes to levy schemes occur is a large uncertainty in the future.

771

772 4. Discussion.

773

The coming decade is likely to see more challenges, and as a consequence changes, in the

775 food system than has been experienced in the recent past. By understanding the system

776 surrounding food consumption and trade, we can gain an insight into the associated impacts on

777 microbial food safety. This provides a useful first step for planning, development of strategies,

778 and prioritisation of actions.

779 Through a system-based approach, this paper explored plausible global and regional

780 trends in future food consumption and its consequences for the burden of disease as related to

781 food with emphasis on the European Union context. The key drivers and associated uncertainties

782 include the following: 
1. Food prices. These are likely to remain at elevated levels and future food availability is likely to become an important issue globally, though possibly less so in the EU. High oil, gas and energy prices, increased biofuel feedstock production, climate change, changing diets and increased world food demand all contribute to this trend. Pressures on food prices and food availability could lead to a reduction of consumption of expensive foods and foods that are land and resource intensive to produce (e.g. meat, especially beef). This then could cause an increase in consumption of foods that experience a lower level of price inflation. The latter could be a consequence also of the recent global economic downturn, with the concomitant loss of affluence in many parts of the world. The exact manifestation of any dietary shift(s) could have a significant impact on the magnitude and nature of the foodborne disease burden. policy as an example EU policy, on the one hand, trade agreements and reform of the EU Common Agricultural Policy would allow more countries access to EU markets. However, this could be countered by increased transport costs and the productivity of most other regions being reduced, relative to the EU, due to climate change. However, for foods imported into the EU from new trade-partner countries, it is important to consider foodborne-disease problems arising in the exporting country or region as, depending on the foodstuff and the nature of the hazard, they could impact on microbial food safety in the EU. It is recognised that there are several key uncertainties associated with global trade that would impact on foodborne disease via food consumption and behaviour. These include the reform of the Common Agricultural Policy, development of trade links and structural changes in the food supply network.

3. Climate change. The threat of climate change could lead to taxation or other levy systems being extended to all parts of food production. If such mechanisms were implemented, this 

would put further pressure on prices and availability of food types and production methods

808 associated with high levels of greenhouse gas emissions. This could create a shift away from 809 meats (again, beef being particularly affected) and reduced use of synthetic nitrogen-based

810 fertiliser. Key uncertainties here would include: the extent and impact of climate change and 811 the degree to which different sectors of agriculture and food manufacturing adapt, and 812 implementation of policies relating to greenhouse gas emissions at both the national and $813 \quad$ international level;

8144. Demographics. An anticipated doubling of the global demand for food and international trade 815 in food in the next few decades is considered as the most significant factor that will drive an 816 increase in food-borne disease with a high degree of certainty. It is highly likely that the 817 population of Europe will possess a higher proportion of older people in the future. This could 818 put upwards pressure on the number and particularly the severity of foodborne disease cases.

819 Furthermore, migration may change food consumption and preparation behaviour, thus altering 820 the patterns of foodborne disease. Key uncertainties regarding the actual magnitude of this driver 821 are linked to the actual extent that underlying drivers shape up, including migration into and out 822 of Europe, evolution of consumer preferences and doubling of global demand for food.

823 Overall, increased consumption of certain food commodities known to be associated with

824 foodborne microbial hazards will increase foodborne illness with a reasonably high degree of 825 certainty. Examples here would include meat and poultry, driven by an increased ability to pay 826 for high protein foods and fresh produce, driven by a trend towards health. Another factor that 827 could increase burden of foodborne diseases, but with less certainty, is the increase in refrigerated 828 foods and extended shelf-life foods driven by a trend towards the desire for convenient foods.

829 The use of effective regulatory measures is considered a factor in our ability to reduce the food 830 borne disease burden with a reasonably high degree of certainty given past experience. Other 
831 factors important to the ability to reduce the burden of foodbone diseases are the development

832 and use of new food safety technologies and detection methods. The most important factor in

833 reducing food-borne disease is likely our ability to first detect and investigate a food safety issue

834 and then to develop effective control measures.

835 The certainty with which measures can be developed and effectively used to control new

836 food safety issues in an ever more complex and changing global food supply is ultimately

837 investment driven. Investment is required to develop the critical resources and infrastructure to

838 develop effective global surveillance of foodborne diseases as well as to fund research on

839 microbial hazards and their control. International developments in risk assessment and risk

840 management techniques offer the potential to shorten the time taken to develop effective and

841 practical control measures through their ability to handle complex food safety issues in food

842 chains. However, their wide spread implementation will require the effective communication and

843 alignment with existing risk management tools such as HACCP and this will again require

844 investment. Although the present study is rudimentary and qualitative in nature, it illustrates that

845 economical returns on investments are possible through food safety research and improvements

846 in infrastructure. The use of complex modelling techniques could be useful in the development of

847 a more quantitative cost-benefit study on food safety investment as well as providing valuable

848 insight into the most effective areas to target investment in order to maximize the return to public

849 health as well facilitating trade.

850 The trends signalled underscore the importance of having reliable surveillance data and

851 systems regionally or even globally, as these could help to monitor new threats and to respond

852 quickly, but also would assist tracking the success of newly introduced control measures.

853 Considering the global context, a notable initiative that the WHO has established is the

854 Foodborne Disease Burden Epidemiology Reference Group (WHO, 2008) which has been set-up 
855 to estimate the global burden of foodborne diseases. Given the growing reliance on food imports

856 from both developed and less developed countries, it is a challenge for national governments to

857 protect their consumers while facilitating fair trade. Conceivably, a country cannot solely rely on

858 its own food safety management systems but would best share best practices and experiences in

859 food safety management with its trading partners. In this regard, international standard setting

860 bodies such as Codex Alimentarius might play a helpful role by the development of equivalent

861 food standards aimed at reducing the burden of global diseases and facilitating international trade

862 in food.

863

864 Acknowledgement.

865 The views expressed in this paper are those of the authors and should not necessarily be

866 ascribed to the Food Standards Agency. Authors TQ and PC thank the Foods Standards Agency

867 (UK) for provision of resources, and colleagues in the Analysis and Research Division for useful

868 discussion and comments. Malcolm Kane (Head of Food Safety, Sainsbury's Supermarkets Ltd,

869 1980-2000) is thanked for insight into the food supply network. 


\section{References}

871

872

873

874

875

876

877

878

880

881

882

883

884

885

886

887

888

889

890

891

892

Adak, G.K., Long, S.M., and O’Brien, S.J., 2002. Intestinal infection: Trends in indigenous foodborne disease and deaths, England and Wales: 1992 to 2000. Gut 51, 832-841.

Adak, G.K., Meakins, S.M., Yip, H., Lopman, B.A., O’Brien, S.J., 2005. Disease Risks from Foods, England and Wales, 1996-2000. Emerging Infectious Diseases, 11, 365-372.

Barbosa-Canovas, G.V., Pothakamury, U. R., Palou, E., and Swanson, B.G. (eds.) 1998. Food Irradiation. In Nonthermal Preservation of Foods. Marcel Dekker, inc., New York: pp. 161-213.

Batz, M.B., Doyle, M.P., Morris, J.G., Jr., Painter, J., Singh, R., Tauxe, R.V., Taylor, M.R., Wong, D.M.A.L.F., 2005. Attributing illness to food. Emerging Infectious Diseases, 11, 993-999.

BIOHAZ, 2007. Scientific Opinion of the Panel on Biological Hazards on a request from the European Commission on Request for updating the former SCVPH opinion on Listeria monocytogenes risk related to ready-to-eat foods and scientific advice on different levels of Listeria monocytogenes in ready-to-eat foods and the related risk for human illness. The EFSA Journal, 599, 1-42

Brul, S., Schuren, F., Montijn, R., Keijser, B.J.F., van der Spek, H. And Oomes, S.J.C.M. 2006. The impact of functional genomics on microbiological food quality and safety. Internatonal Journal of Food Microbiology, 112, 195-199

Brul, S., Mensonides, F.I.C., Hellingwerf, K.J. and Teixeira de Mattos, M.J. 2008. Microbial Systems Biology; new frontiers open to Predictive Microbiology. International Journal of Food Microbiology 128, 16-21 
893

894

895

896

897

898

899

900

901

902

903

904

905

906

907

908

909

910

911

912

913

914

915

916

Bruhn, C.M., 1998. Consumer Acceptance of Irradiated Food: Theory and Reality. Radiation Physics and Chemistry, 52 (1-6), 129-133.

Burt, G., van der Heijden, K., 2003. First steps: towards purposeful activities in scenario thinking and future studies. Futures, 35, 1011-1026.

CAC, 2007, Principles and Guidelines for the Conduct of Microbiological Risk Management, CAC/GL 63-2007.

CAC, 2008, Code of Hygienic Practice for Powdered Formulae for Infants and young Children, CAC/RCP 66-2008.

Cheftel, J.C. 1992. Effects of high hydrostatic pressure on food constituents: an overview. In: High Pressure and Biotechnology. C. Balny, R. Hayashi, K. Heremans, and P. Masson (eds.). Colloque INSERM/John Libbey Eurotext Ltd., London: Vol. 224, pp. 195-209.

Chesher, A., Lechene, V., 2002. Demand Analysis of the National Food Survey, Project report for the Food Standards Agency (UK), Food Standards Agency (UK) working document (unpublished).

Cheung, S.-L., Olsen, W., Southerton, D., Warde, A., 2007. The changing practice of eating: evidence from UK time diaries 1975 and 2000. British Journal of Sociology, 58, 39-61.

CSPI (Center for Science in the Public Interest), 2005. Global and Local: Food Safety Around the World. CSPI, Washington DC. Available at: http://www.cspinet.org/new/pdf/global.pdf (Accessed 27-7-2009).

CSPI, 2006, Outbreak Alert Data: Info on Produce Outbreaks. Available at: http://www.cspinet.org/new/pdf/cspi_outbreak_alert.pdf (accessed 27-7-2009).

Datamonitor, 2006. Changing cooking behaviours and attitudes: beyond convenience. Report number: DMCM2983.

Datamonitor. 2008. Changing Grocery Shopping Patterns. Report number: DMCM4619. 
917 Denny, J., McLauchlin, J., 2008. Human Listeria monocytogenes infections in Europe - an

918 opportunity for improved European surveillance, Eurosurveillance, available at:

919 http://www.eurosurveillance.org/ViewArticle.aspx?ArticleId=8082 (accessed 27-7-2009).

920 DOH/HPA (Department of Health/Health Protection Agency), 2008. Health Effects of Climate

921 Change in the UK 2008: An update of the Department of Health Report 2001/2002.

$922 \quad$ Product number 285576. Available at:

923 http://www.dh.gov.uk/en/Publicationsandstatistics/Publications/PublicationsPolicyAndGu

924 idance/DH_080702 (accessed 27-7-2009).

925 Eastwood, G. 2006. Growth Strategies in Ready Meals, Business Insights Ltd.

926 Eurostat (2008a). Agriculture and fisheries statistics; data downloaded from:

927 http://www.ec.europa.eu/eurostat on 31 $\quad$ March 2008.

928 Eurostat (2008b) External trade statistics: EU27 trade since 1995 by SITC; data downloaded

929 from: http://www.ec.europa.eu/eurostat on $2^{\text {nd }}$ April 2008.

930 Evers, E.G., van der Fels-Klerx, H.J., Nauta, M.J., Schijven, J.F., Havelaar, A.H., 2008.

931 Campylobacter source attribution by exposure assessment. International Journal of Risk

$932 \quad$ Assessment and Risk Management 8 (1-2), 174-190.

933 Expenditure and Food Survey, accessed 2008. Statistics from Department of Environment, Food

934 and Rural Affairs (UK), downloaded from:

935 https://statistics.defra.gov.uk/esg/publications/efs/default.asp on 14 April 2008.

936 FAO (Food and Agriculture Organisation of the UN), 2008: Agricultural price index - data

937 downloaded from http://www.fao.org/worldfoodsituation/FoodPricesIndex/en/ on 14

$938 \quad$ April 2008.

939 FAO, 2009. The State of Agricultural Commodity Markets - available at

$940 \quad$ ftp://ftp.fao.org/docrep/fao/012/i0854e/i0854e.pdf 
941 FAO/WHO, 2004, Enterobacter sakazakii and other microorganisms in powdered infant formula.

942 Meeting report. Microbiological Risk Assessment Series 6. ISBN: 92-5-105164-X.

943 FAO/WHO, 2008. Microbiological hazards in fresh leafy vegetables and herbs. Meeting report

944 Microbiological Risk Assessment Series 14. ISBN 978-92-5-106118-3.

945 Farkas, J., 1998. Irradiation as a method for decontaminating food. International Journal for Food

$946 \quad$ Microbiology, 44:189-204.

947 Food Safety Magazine Expert Panel Panel, 2007. The Challenge of Bacterial Spores (Category:

948 Shelf Stable, Low Acid Foods). Available at:

949 http://www.foodsafetymagazine.com/article.asp?id=1176\&sub=sub1 (accessed 27-7-

950 2009).

951 FSA (Food Standards Agency), 2007a. Annual Report of the Chief Scientist 2006/7. Available at: http://www.food.gov.uk/multimedia/pdfs/board/fsa071005a.pdf (accessed 27-7-2009).

953 FSA, 2007b. Consumer Attitudes to Food Standards, Wave 7. COI Reference 275516.

954 FSIS (USDA Food Safety and Inspection Service), 2006. Indiana Firm Recalls Frozen Stuffed Chicken Entrees Associated With Illnesses. http://www.fsis.usda.gov/News_\&_Events/RECALL_009_2006_RELEASE/index.asp (accessed 27-7-2009).

958 Gillespie, I.A., McLauchlin, J., Grant, K.A., Little, C.L., Mithani, V., Penman, C., Lane, C., 959 Regan, M., 2006. Changing pattern of human listeriosis, England and Wales, 2001-2004. 960 Emerging Infectious Diseases, 12, 1361-1366.

961 Gillespie I.A., O’Brien S.J., Frost, J. (on behalf of the Campylobacter Sentinel Surveillance 962 Scheme collaborators), 2005. Campylobacter Sentinel Surveillance Scheme - third and 963 final report (1st May 2000 to 30th April 2003). Health Protection Agency. Unpublished. 
964 Global Environment Facility, 2002. The Challenge of Sustainability. An action agenda for the

965 global environment. ISBN 1-884122-79-5.

966 Gorris, L.G.M., J. Bassett, J.-M. Membré, 2006. Food Safety Objectives and related concepts: the

967 role of the food industry. In: Emerging foodborne pathogens (Y. Motarjemi, M. Adams, 968 eds). Woodhead Publ. ISBN 1-85573963-1.

969 Goulet, V., Hedberg, C., Le Monnier, A., de Valk, H., 2008. Increasing incidence of listeriosis in $970 \quad$ France and other European countries. Emerging Infectious Diseases, 14, 734-740.

971 Grove, S.F., Lee, A, Lewis, T., Stewart, C.M., Chen, H. and Hoover, DG. 2006. Inactivation of 972 foodborne viruses of significance by high pressure and other processes. Journal of Food $973 \quad$ Protection, 69 (4), 957-968.

974 Hald, T., Vose, D., Wegener, H.C., Koupeev, T., 2004. A Bayesian approach to quantify the 975 contribution of animal-food sources to human salmonellosis. Risk Analysis, 24, 255-269.

976 Havelaar, A.H., Brul, S., Jong, A. de, Jong, R. de, Zwietering, M.H. and TerKuile, B. 2009. Future challenges to microbial food safety. International Journal of Food Microbiology (accepted; special issue "Future Challenges to Food Safety”, organised by the Dutch Food and Consumer Products Safety Authority (VWA) and the European Food Safety Authority (EFSA)

Hoover, D. G. 1997. Minimally processed fruits and vegetables: Reducing microbial load by nonthermal physical treatments. Food Technology 51, 66-71.

983 Hughes, C., Gillespie, I.A., O’Brien, S.J., The Breakdowns in Food Safety Group, 2007. Foodborne transmission of infectious intestinal disease in England and Wales, 1992-2003. Food Control, 18, 766-772.

ICMSF (International Commission on the Microbiological Specifications for Food), 2002. Microorganisms in Foods. Book 7. Microbiological Testing in Food Safety Management. Kluwer Academic/Plenum, NY. ISBN 0-306-47262-7. 
989 ICMSF (International Commission on the Microbiological Specifications for Food), 2006. Use of 990 epidemiologic data to measure the impact of food safety control programs. Food Control,

991

992

993

994

995

996

997

998

1000

1001

1002

1003

1004

1005

1006

1007

1008

1009

1010

1011

1012 $17,825-837$.

International Panel on Climate Change, 2007. Summary for Policymakers. In: Parry, M.L., Canziani, O.F., Palutikof, J.P., van der Linden P.J., Hanson, C.E., (Eds.), Climate Change 2007: Impacts, Adaptation and Vulnerability. Contribution of Working Group II to the Fourth Assessment Report of the Intergovernmental Panel on Climate Change, Cambridge University Press, Cambridge, UK, 7-22. Available at: http://www.ipcc.ch/pdf/assessmentreport/ar4/wg2/ar4-wg2-spm.pdf (accessed 27-7-2009).

Kemmeren, J.M., Mangen, M.-J.J., van Duynhoven, Y.T.H.P., Havelaar A.H., 2006. Priority setting of foodborne pathogens. Disease burden and costs of selected enteric pathogens. RIVM report 330080001/2006.

Koutchma, T., Paris, B., Patazca, E. 2007. Validation of UV coiled tube reactor for fresh juices. Journal of Environmental Engineering and Science, 6 (3), 319-328.

Llorens Abando, L., Martinex Palou, A.-M., 2006. Main stages in the meat food chain in Europe, Statistics in Focus, Eurostat. Available at: http://www.edsdestatis.de/en/downloads/sif/nn_06_06.pdf (accessed 27-7-2009).

Lynch, M., Painter, J., Woodruff, R., Braden, C., 2006. Surveillance for foodborne disease outbreaks - United States, 1998-2002. Morbidity and Mortality Weekly, 55, 1-34.

McLauchlin, J., Hall, S.M., Velani, S.K., Gilbert, R.J. 1991. Human listeriosis and paté: a possible association. British Medical Journal, 303, 773-775.

Mead P.S., Slutsker L., Dietz V., McCaig L.F., Bresee J.S., Shapiro C., Griffin P.M., Tauxe R.V., 1999. Food-related illness and death in the United States. Emerging Infectious Diseases, 5, 607-625. 
1013 Meziane, Z., 2007. Future Innovations in Food and Drinks to 2012, Business Insight Ltd.

1014 Monk, J.D., Beuchat, L.R., Doyle, M.P. 1995. Irradiation inactivation of food-borne

1015 microorganisms. Journal of Food Protection, 58, 197-208.

1016 OECD/FAO (Organisation for Economic Co-operation and Development / Food and Agriculture

1017 Organisation of the United Nations), 2007. OECD-FAO Agricultural outlook 2007-2016.

1018 OECD, Paris, France (OECD report 88353).

1019 OECD/FAO, 2009. Agricultural Outlook 2009-2018. OECD Publishing, Paris, France. ISBN:

$1020 \quad 9789264044777$.

1021 Ontario MoH (Ontario, Ministry of Health and Long-Term Care), 2009. Chief Medical Officer of 1022 Health's report on the management of the 2008 listeriosis outbreak in Ontario. Ministry of 1023 Health and Long-Term Care. ISBN: 9781424993437.

1024 Onwulata, C.I., Flora, L.F., Kramer, W.H. 2008. R\&D needs and opportunities in food science and technology. Food Technology, 62(11), 41-47.

1026 Qin, B.L. Pothakamury, U.R., Barbosa-Canovas, G.V., Swanson, B.G. 1996. Nonthermal pasteurization of liquid foods using high intensity pulsed electric fields. Critical Reviews in Food Science and Nutrition, 36 (6), 603-627.

Radomyski, T., Murano E.A., Olsen D.G.,. Murano, P.S., 1994. Elimination of pathogens of significance in food by low-dose irradiation: a review. Journal of Food Protection, 57, 7386.

1032 Regmi, A., Deepak, M.S., Seale Jr., J.L., Bernstein, J., 2001. Cross-country analysis of food consumption patterns, In: Regmi, A. (Ed.), Changing Structure of Global Food Consumption and Trade, US Department of Agriculture, pp. 14-22.

1035 Rocourt, J., Moy, G., Vierk, J. Schlundt, J. 2003. The present state of foodborne disease in OECD 1036 countries. Food Safety Department, WHO, Geneva. ISBN 9241591099. 
1037 Sale, A.J.H., Gould G.W., Hamilton, W.A. 1970. Inactivation of bacterial spores by hydrostatic

1038 pressure. Journal of General Microbiology, 60, 323-334.

1039 Schmidhuber, J., 2003. The outlook for long-term changes in food consumption patterns:

1040 concerns and policy options. Available at: www.fao.org/es/ESD/Schmidhuberdiets.pdf

$1041 \quad$ (Accessed 27-7-2009).

1042 Scott J., Huffman R., 2007, Listeria control in processed foods. How far have we come and

1043 where do we go from here? ISOPOL XVI presentation. Available at:

1044 http://www.aphl.org/profdev/conferences/proceedings/Documents/2007_ISOPOL/Listeria

1045 _Control_and_Processed_Foods.pdf (Accessed 27-7-2009).

1046 Shigehisa, T., T. Ohmori, A. Saito, S. Taji, and R. Hayashi. 1991. Effects of high pressure on

1047 characteristics of pork slurries and inactivation of microorganisms associated with meat

1048 and meat products. International Journal of Food Microbiology, 12, 207-216.

1049 Smelt, J.P.P.M., 1998. Recent advances in the microbiology of high pressure processing. Trends

1050 in Food Science and Technology, 9,152-158.

1051 Stevens, C., Keane, J., 2008. Biofuels and development: will the EU help or hinder? Overseas

1052 Development Institute briefing paper number 32, ISSN 0140-8682.

1053 Stevens, C., Meyn, M., Keenan, J., 2008. Duty-free, quota-free access: Duty-free, quota-free

1054 access: What is it worth? Overseas Development Institute briefing paper number 10, ISSN

$1055 \quad$ 1756-7602.

1056 Stewart, C.M., Cole, M.B. 2001. Preservation by the application of nonthermal processing, pp.

1057 53-61. In C. J. Moir, C. Andrew-Kabilafkas, G. Arnold, B. M. Cox, A. D. Hocking, and I.

1058 Jenson (eds.), Spoilage of processed foods: Causes and diagnosis. Australian Institute of

1059 Food Science and Technology Incorporated, Waterloo DC, Australia. 
1060 Sudan I Review Panel, 2007. Report of the Sudan I review panel. Food Standards Agency report $1061 \quad$ FSA/1193/0807.

1062 Tansey, G., 2008. A Changing Food System. In: Tansey, G., Rajotte, T. (Eds.), The Future

1063 Control of Food. Earthscan, London and Sterling, pp. 1-24.

1064 Thompson, R., 2007. Where are the best policies to promote Ag-related R\&D. Presented at the

1065 Federal Reserve Bank of Chicago conference on the role of R\&D in Agriculture and 1066 related industries: Today and Tomorrow.

1067 http://www.chicagofed.org/news_and_conferences/conferences_and_events/files/2007_ag 1068 thompson.pdf (accessed 27-7-2009).

1069 Tiffin, R., Arnoult, M., Irz, X., 2007. Distinguishing between the impact of economic and social 1070 conditions as contributory factors leading to poor dietary choice (unpublished).

1071 Timson, W.J. and A.J. Short. 1965. Resistance of microorganisms to hydrostatic pressure.

1072 Biotechnology and Bioengineering, 7, 139-159.

1073 Tompkin, B. 2007, Control of Emerging Pathogens (An Industry Perspective) Presented at the 1074 ICMSF - ILSI Symposium on Current and Innovative Approaches to Microbial Food 1075 Safety Management, 3-4, October 2007, Singapore.

1076 UK Prime Minister’s Strategy Unit, 2008. Food: an analysis of the issues. Available online at: 1077 http://www.cabinetoffice.gov.uk/strategy/work_areas/food_policy.aspx (Accessed 27-71078 2009).

1079 United Nations World Populations Prospects, 2006. United Nations World Populations Prospects 2006 Revision. Downloaded from: http://esa.un.org/unpp/ on $2^{\text {nd }}$ April 2008.

1081 van Gerwen, S.J.C., Rombouts, F.M., van 't Riet, K. and M.H. Zwietering, 1999. A data analysis 1082 of the irradiation parameter D10 for bacteria and spores under various conditions. Journal 1083 of Food Protection 62, 1024-1032. 
1084 Vojdani, J.D., Beuchat, L.,R. and Tauxe, R.V. 2008, Juice-Associated Outbreaks of Human

1085 Illness in the United States, 1995 through 2005, Journal of Food Protection, 71, 356-364.

1086 WHO (World Health Organisation), 2008. WHO Initiative to Estimate the Global Burden of

1087 Foodborne Diseases. Available at:

1088 http://www.who.int/foodsafety/publications/newsletter/ferg_special/en/ (Accessed 27-7-

1089 2009).

1090 World Bank, 2005. World Development Indicators database. Available at

$1091 \quad$ www.worldbank.org/data (accessed 27-7-2009)

1092 WTO (World Trade Organisation), 1995. The WTO Agreement on the Application of Sanitary

1093 and Phytosanitary Measures (SPS Agreement). Available at:

1094 http://www.wto.org/english/tratop_e/tratop_e.htm (accessed 27-7-2009).

1095 Zhe Jin, G., Leslie, P., 2003. The effect of information on product quality: evidence from

1096 restaurant hygiene grade cards. Quarterly Journal of Economics, 118, 409-451.

1097 


\section{Legends of Tables}

1099

1100 Table 1. Estimated proportion of indigenous foodborne disease, by food group and type for

1101 England and Wales, 1996-2000 (source: Adak et al., 2005).

1102

1103 Table 2. Summary of economic indicators for several food groups. A. self-sufficiency of meats in

11042002 for the EU15 (Source: Eurostat accessed, 2008a); B. price elasticitities by food group in the

1105 UK for all income brackets. (Tiffin, Arnoult and Irz, 2007); C. price change of meat by type

1106 (1996-2002, EU15), adjusted for inflation (Source Eurostat, 2008a).

1107

1108 Table 3. Population density data (multiple of million inhabitants) for several countries with

1109 indication of population fraction with income levels below $1 \$$ /day and < 2\$/day (source: Source:

1110 World Bank, 2005). 


\section{Legends of Figures}

1113 Figure 1. Selection of driving factors in different categories that influence consumption of a

1114 single food type.

1115

1116 Figure 2. Visual representation of the key factors likely to impact on foodborne disease. Whether

1117 factors are likely to increase or decrease the global burden of foodborne disease is plotted against

1118 the certainty of their impact.

1119

1120 Figure 3. Price elasticities in food in Great Britain for mid-income bracket showing the median

1121 (O) with error bars representing one standard error of the mean (Chesher and Lechene, 2002). 1122 .

1123 Figure 4. A (Left panel): factors other than demand affecting the food supply price; B (right 1124 panel): influences on demand of consumption of a single food other than price and income.

1125

1126 Figure 5. A (top panel): gross human apparent consumption (mass) per head of selected major

1127 food groups in the EU 1991-2003; 4 B (bottom panel): gross human apparent consumption per

1128 head of population in the EU of various types of meat (1995 to 2002), indexed to 1995 level.

1129 From Eurostat: agriculture and fisheries statistics (Eurostat, 2008).

1130 
Figure 1. (Quested et al.)

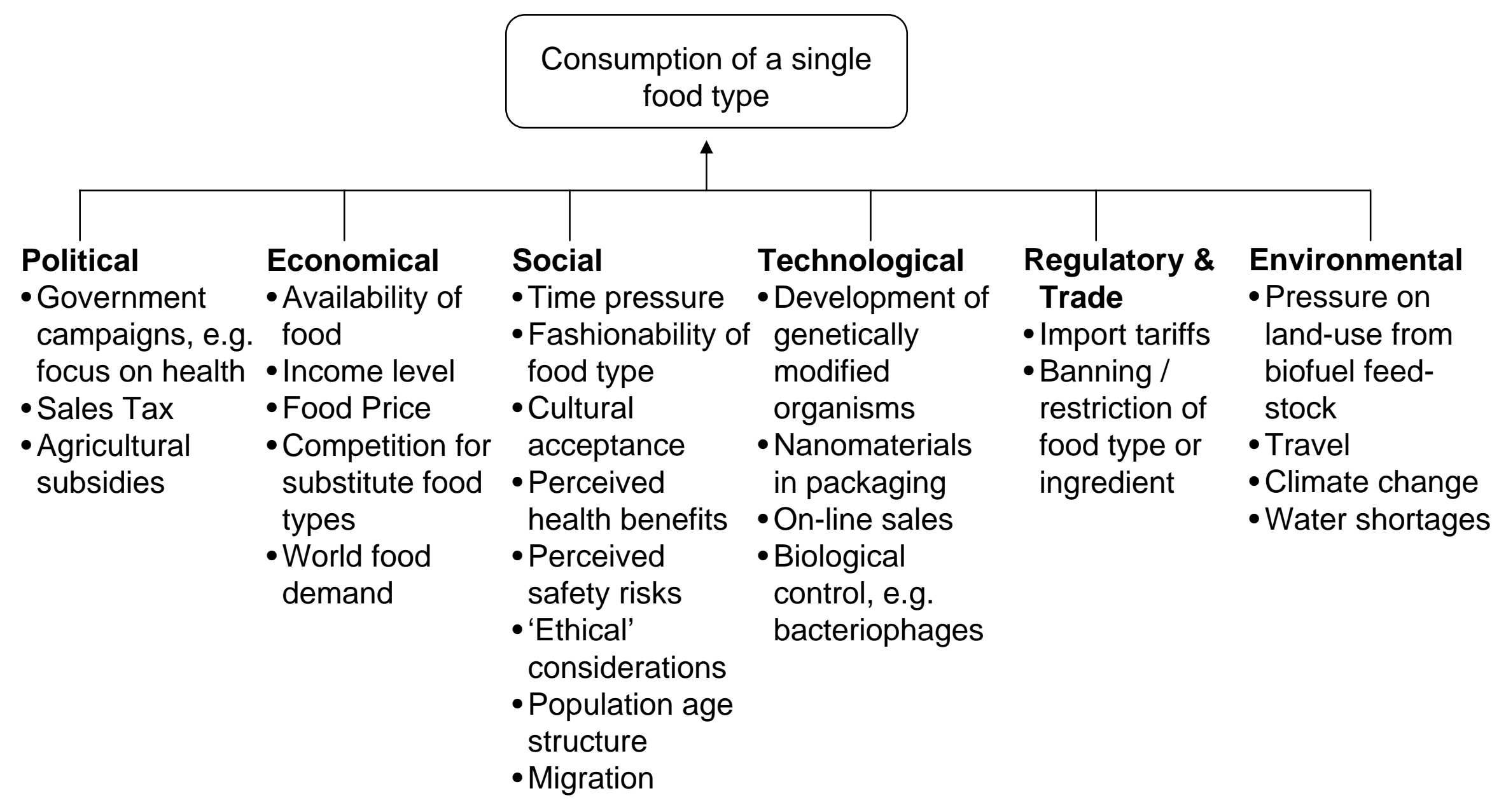


Figure 2. (Quested et al.)

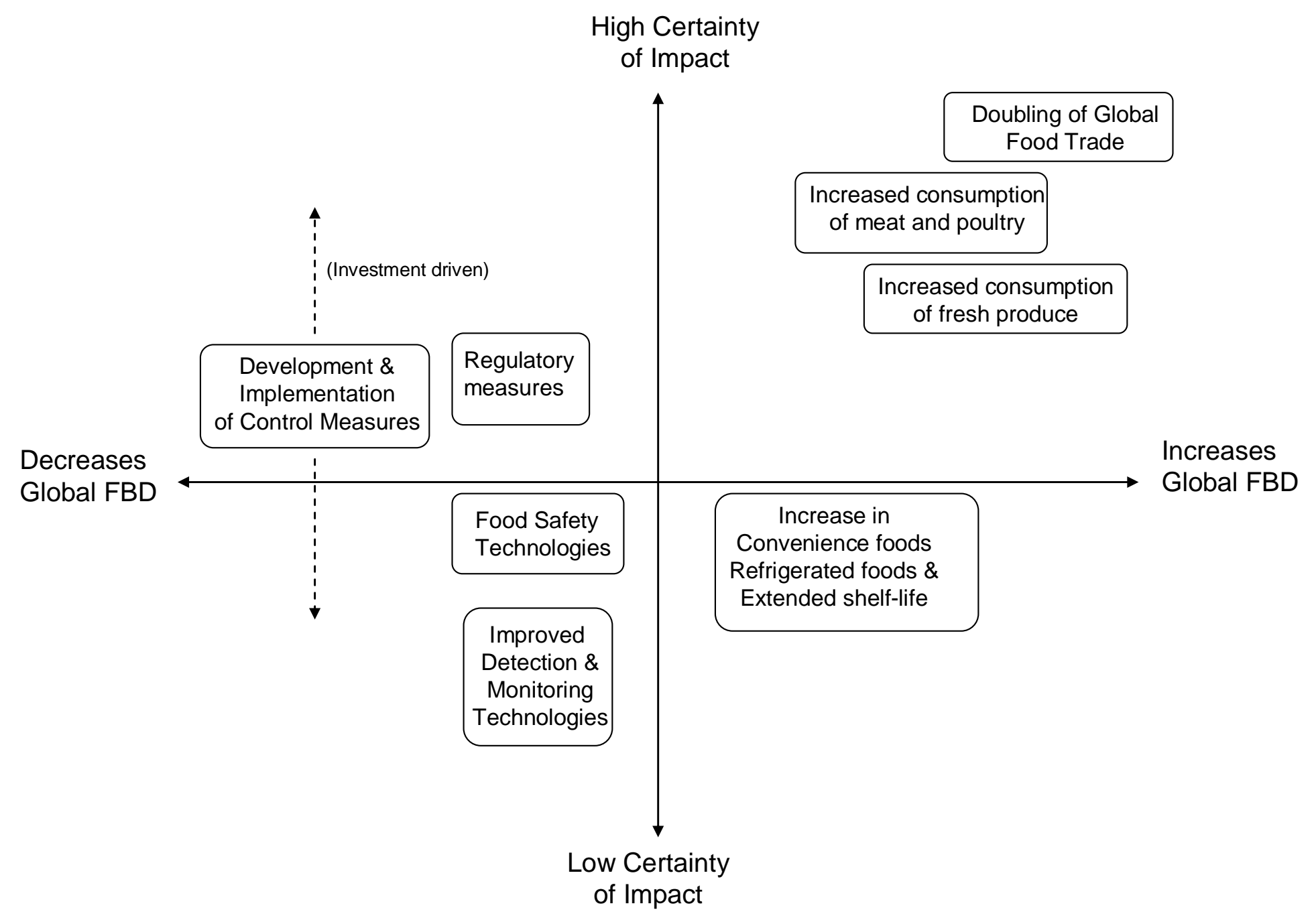


Figure 3. (Quested et al.)

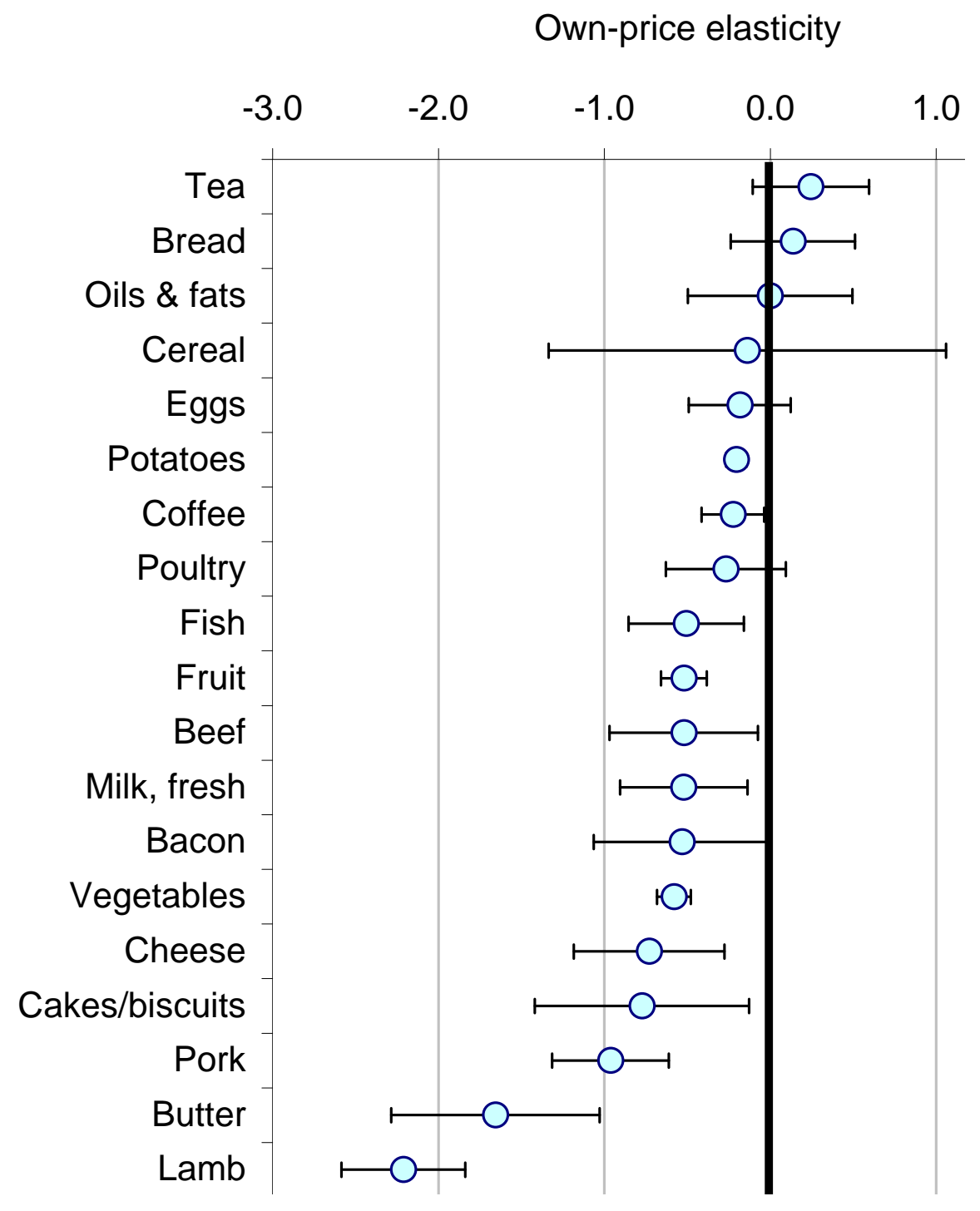


Figure 4A (left panel) and 4B (right panel) (Quested et al.)
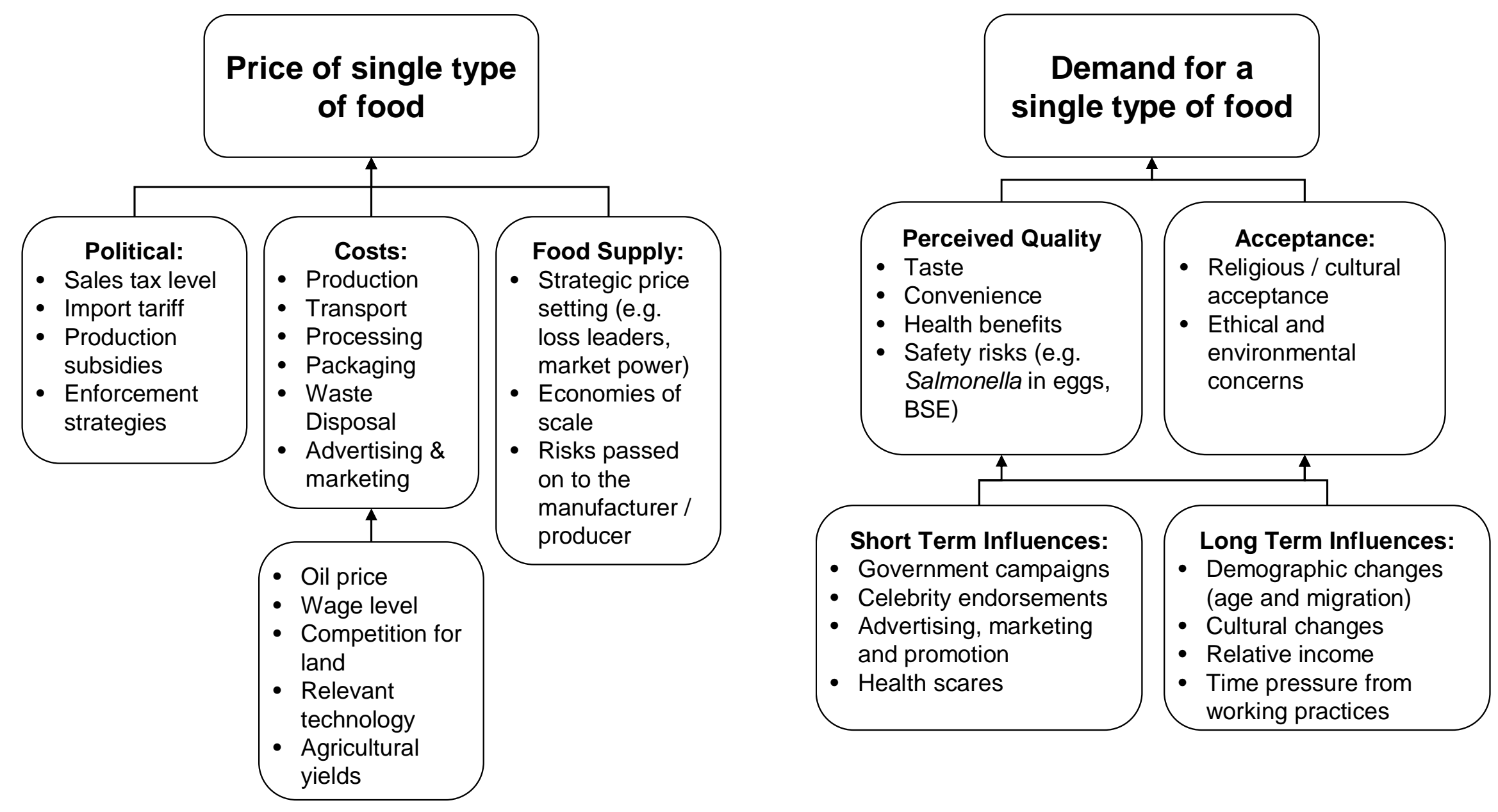
Figure 5A (top panel) and 5B (bottom panel) (Quested et al.)
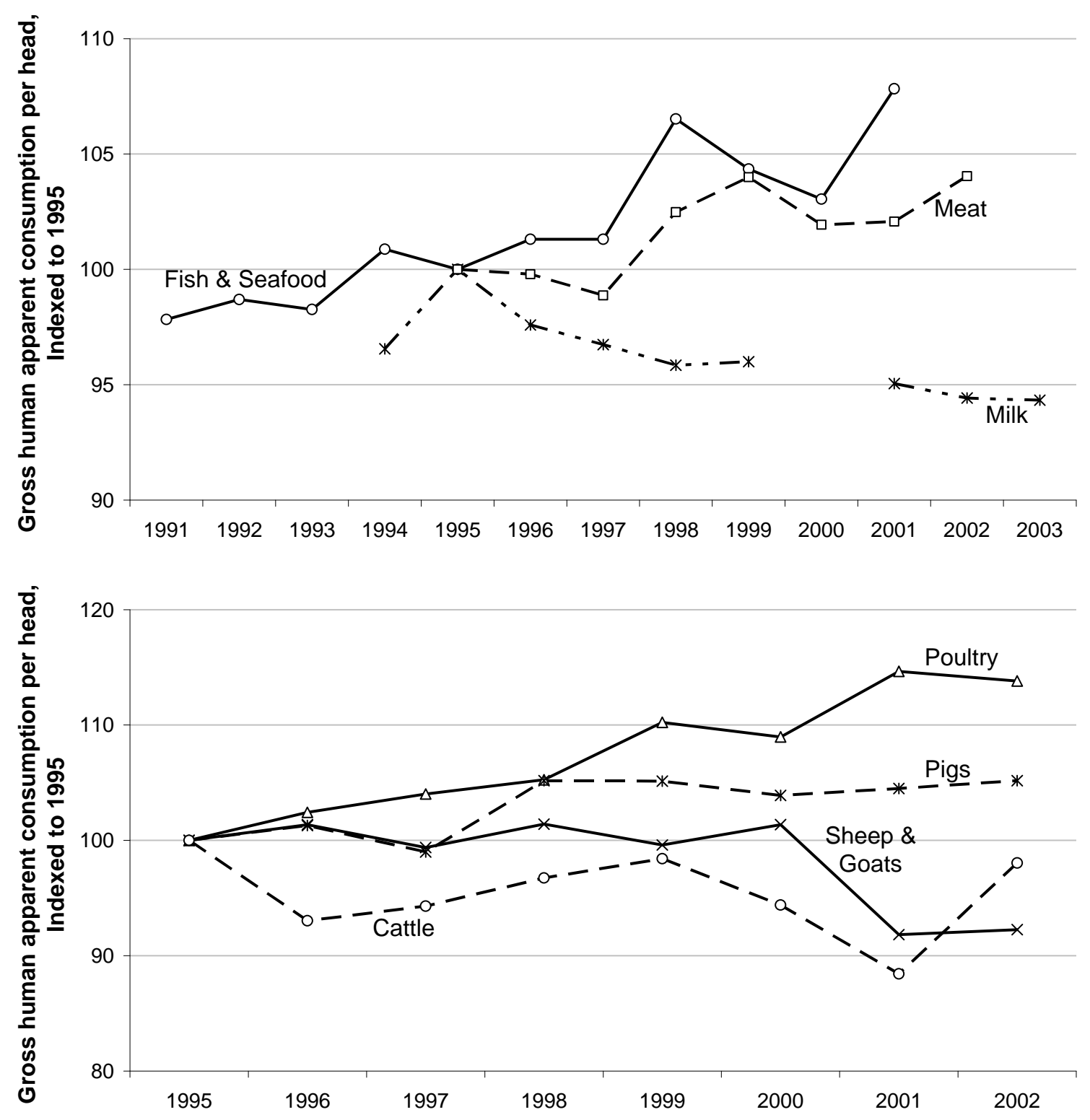
Table 1 (Quested et al.)

Table 1. Estimated proportion of indigenous foodborne disease, by food group and type for England and Wales, 1996-2000 (source: Adak et al., 2005).

\begin{tabular}{|c|c|c|}
\hline Food Group / Type & Cases (\%) & Deaths (\%) \\
\hline Poultry & 29 & 28 \\
\hline Chicken & 23 & 21 \\
\hline Turkey & 5 & 7 \\
\hline Mixed / unspecified & 1 & 1 \\
\hline Eggs & 6 & 7 \\
\hline Red Meat & 17 & 24 \\
\hline Beef & 7 & 10 \\
\hline Pork & 3 & 4 \\
\hline Bacon / Ham & 1 & 1 \\
\hline$L a m b$ & 3 & 4 \\
\hline Mixed / unspecified & 4 & 5 \\
\hline Seafood & 7 & 4 \\
\hline Fish & 1 & 2 \\
\hline Shellfish & 4 & 2 \\
\hline Mixed / unspecified & 1 & 1 \\
\hline Milk & 6 & 5 \\
\hline Other dairy products & 0 & 0 \\
\hline Vegetables / fruit & 3 & 2 \\
\hline Salad vegetables & 2 & 2 \\
\hline Cooked vegetables & 0 & 0 \\
\hline Fruit & 0 & 0 \\
\hline Rice & 2 & 1 \\
\hline Complex foods & 26 & 26 \\
\hline Infected food handler & 4 & 2 \\
\hline
\end{tabular}


Table 2. Summary of economic indicators for several food groups. A. selfsufficiency of meats in 2002 for the EU15 (Source: Eurostat accessed, 2008a); B. price elasticitities by food group in the UK for all income brackets. (Tiffin, Arnoult and Irz, 2007); C. price change of meat by type (1996-2002, EU15), adjusted for inflation (Source Eurostat, 2008a).

\begin{tabular}{|l|l|l|c|}
\hline & Parameter & Food group / type & Value \\
\hline & & & \\
\hline A & Self-sufficiency (\%) & Meat - total & 106 \\
\hline & & Cattle & 101 \\
\hline & & Pigs & 109 \\
\hline & & Sheep and goats & 81 \\
\hline & & Poultry & 107 \\
\hline & & & \\
\hline B & Own-price elasticity & & \\
\hline & & Meat, fish \& alternatives & -0.88 \\
\hline & & Cereals \& potatoes & -0.66 \\
\hline & & Fruit \& vegetables & -0.66 \\
\hline & & Fats \& sugar & -0.52 \\
\hline & & Milk \& dairy & -0.40 \\
\hline & & & \\
\hline C & Change between 1996 and 2002 (\%) & Meat total & -19.6 \\
\hline & & Cattle & -12.1 \\
\hline & & Pigs & -26.5 \\
\hline & & Sheep and goats & -9.7 \\
\hline & & Poultry & -19.6 \\
\hline
\end{tabular}


Table 3 (Quested et al.)

Table 3. Population density data (multiple of million inhabitants) for several countries with indication of population fraction with income levels below $1 \$ /$ day and < 2\$/day (source: Source: World Bank, 2005).

\begin{tabular}{|l|c|c|c|}
\hline Country & Population (x 10 & $\mathbf{\%}<\mathbf{1} \mathbf{\text { day }}$ & $\mathbf{\%}<\mathbf{2} \mathbf{\text { dday }}$ \\
\hline China & 1299 & 16.6 & 46.7 \\
\hline India & 1065 & 34.7 & 79.9 \\
\hline Indonesia & 239 & 7.5 & 52.4 \\
\hline Brazil & 184 & 8.2 & 22.4 \\
\hline Pakistan & 159 & 13.4 & 23.8 \\
\hline Russia & 144 & 6.1 & 82.8 \\
\hline Bangladesh & 141 & 36.0 & 90.8 \\
\hline Nigeria & 126 & 70.2 & 26.3 \\
\hline Mexico & 105 & 9.9 & \\
\hline
\end{tabular}

